\title{
Communicating Monetary Policy Rules
}

\author{
Troy Davig \\ Symmetry Investments \\ Andrew Foerster \\ Federal Reserve Bank of San Francisco \\ September 2022 \\ Working Paper 2021-12 \\ https://www.frbsf.org/economic-research/publications/working-papers/2021/12/
}

\section{Suggested citation:}

Davig, Troy, Andrew Foerster. 2022 "Communicating Monetary Policy Rules," Federal Reserve Bank of San Francisco Working Paper 2021-12.

https://doi.org/10.24148/wp2021-12

The views in this paper are solely the responsibility of the authors and should not be interpreted as reflecting the views of the Federal Reserve Bank of San Francisco or the Board of Governors of the Federal Reserve System. 


\title{
Communicating Monetary Policy Rules*
}

\author{
Troy Davig ${ }^{\dagger} \quad$ Andrew Foerster ${ }^{\ddagger}$
}

September 12, 2022

\begin{abstract}
Despite the ubiquity of inflation targeting, central banks communicate their frameworks in a variety of ways. No central bank explicitly expresses their conduct via a policy rule, which contrasts with models of policy. Central banks often connect theory with practice by publishing inflation forecasts that can, in principle, implicitly convey their reaction function. We return to this central idea to show how a central bank can achieve the gains of a rule-based policy without publicly stating a specific rule. The approach requires central banks to specify an inflation target, inflation tolerance bands, and provide economic projections. When inflation moves outside the band, inflation forecasts provide a time frame over which inflation will return to within the band. We show how this communication replicates and provides the same information as a rule-based policy. The communication strategy produces a natural benchmark for assessing central bank performance. We illustrate these features in a counterfactual monetary policy history of the United States.
\end{abstract}

Keywords: monetary policy, inflation targeting, Taylor rule, communication

JEL Codes: E10, E52, E58, E61

\footnotetext{
${ }^{*}$ We thank the Editor Peter Rupert, and two anonymous referees, plus Guido Ascari, Francesco Bianchi, Fernando Martin, and participants at the Missouri Macro Workshop, Society for Economic Dynamics, and Midwest Macroeconomics Conferences for helpful comments. Jason Choi provided excellent research assistance. All views expressed are solely those of the author(s) and do not necessarily represent the views of his employer, Symmetry Investments, or its affiliates. The views expressed are solely those of the authors and do not necessarily reflect the views of the Federal Reserve Bank of San Francisco or the Federal Reserve System.

†tdavig@symmetryinvestments.com.

${ }^{\ddagger}$ Federal Reserve Bak of San Francisco, 101 Market Street, San Francisco, CA, 94105, andrew.foerster@sf.frb.org.
} 


\section{Introduction}

Since its advent more than 30 years ago, inflation targeting has become the dominant paradigm for how central banks conduct monetary policy. It would be natural to assume, given experience and the ubiquity of inflation targeting across the globe, questions about how central banks communicate their frameworks and monetary policy decisions would largely be resolved. However, given that no central bank mechanically follows an instrument-based monetary policy rule, such as a Taylor rule, central banks have adopted a variety of approaches in how they communicate their strategy.

Inflation targeting central banks generally seek to follow a systematic monetary policy guided by some underlying rule or optimal monetary policy framework, but are reluctant about turning policy over to a simple rule that may not be appropriate in all circumstances. This reluctance may stem from the idea that, after explicitly specifying a rule, deviations might become more difficult. Consequently, central banks face a challenge in how to convey a monetary policy strategy that is systematic and accountable for achieving some stated objectives, such as an inflation target or full employment, without having to specify a specific interest rate rule.

In this paper, we develop a clear link between rules-based policy and communication. Three ingredients are essential to an effective communication strategy and if combined properly, can replicate the information provided by a policy rule and provide a clear benchmark for accountability. Specifically, we show that specifying a point inflation target, inflation tolerance bands, and economic projections can provide the same information as if a specific policy rule was revealed to the public. This framework allows communicating policy rules by language stating that "inflation will be within the tolerance band in $N$ periods." Further, the communication strategy naturally produces a benchmark for assessing deviations from the rule. Since many central banks already use variants of the three ingredients in how they conduct policy, the framework we study is closer to how policy is conducted in practice than the alternative of using an outright rule.

To illustrate the connection, we use a simple Fisherian model of inflation. Within this framework, an inflation target, tolerance band, and inflation forecast convey the underlying policy rule. For example, when inflation is outside of the band, a wide band combined with a forecast showing a slow return of inflation to a rate inside the band signals an underlying policy rule with a weak response to inflation. A tight band with a forecast showing a rapid return of inflation to within the band conveys a rule with a stronger response to inflation. ${ }^{1}$

\footnotetext{
${ }^{1}$ These results are reminiscent of some of those in Smets (2000), where shorter forecast targeting horizons are
} 
We highlight pitfalls of vague communication and incomplete information how they can fail to convey a policy rule. The communication ingredients also produce a metric for assessing central bank performance; namely, deviations are assessed by comparing stated communication about the forecast for inflation returning within the tolerance band with outcomes. Lastly, we use a small scale model to study a counterfactual history of monetary policy in the US to illustrate how communication would have worked in practice.

While widely accepted in modeling monetary policy, often for its simplicity and approximation to optimal policy (Schmitt-Grohe and Uribe, 2007), in practice no central bank strictly follows a rule. A common rationale for this omission is that mechanical adherence to a rule may misguide practical policy decisions due to the multitude of shocks that commonly impinge on actual economies. For example, setting a single rule could generate inferior outcomes if the rule is improperly specified given the economic environment (Ikeda and Kurozumi, 2014), or in the presence of structural change in the economy (Choi and Foerster, 2019). ${ }^{2}$ Some central banks have addressed this gap between theory and practice by issuing monetary policy reports that include inflation, output, and interest rate projections. Such projections can implicitly convey the central bank's reaction function, which is one of the key points of the inflation-forecast targeting literature (for example, Svensson, 1999, 2002; Svensson and Woodford, 2005; Woodford, 2005).

We build on the insights from inflation-forecast targeting, but emphasize the importance of a tolerance band as a communication device. Failure to specify a band may leave the public with a perception that hitting the target is always far into the future or conveys precision that is not achievable in practice. Even in standard New Keynesian models after a shock, a central bank following a standard Taylor rule hits its inflation point objective only asymptotically, implying that inflation is missing its target with near certainty at all points in time. The failure to hit an exact target can lead to some central banks persistently facing questions about their strategy and how to assess whether they are achieving their objectives (for example, Cochrane and Taylor, 2016; Warsh, 2017).

Thus, one of the beneficial by-products of the approach is that specifying tolerance bands and a horizon for moving back into the band, as indicated by forecasts, provides a clear performance metric with which to assess whether a central bank is meeting its objectives. Walsh (2015)

associated with greater weight on price stability in society's objective function. Relatedly, Battini and Nelson (2001) describe an optimal policy horizon, which is the optimal time for inflation to return to target.

${ }^{2}$ The argument by Fuhrer et al. (2018) to have systematic reviews of policy would somewhat alleviate this latter concern. This practice plays a predominant role at the Bank of Canada, and was recently adopted by the Federal Reserve. 
discusses the importance of such metrics and how they can affect monetary policy actions, while Mishkin and Westelius (2008) relate inflation target bands to the incentives for central bankers originally studied by Walsh (1995). D'Acunto et al. (2020) highlight how communication based upon targets can improve policy effectiveness and strengthen trust in central banks.

While we focus on the communication aspects of inflation bands, a long line of research considers their practical and theoretical advantages. Bernanke and Mishkin (1997) argue that in practice, inflation target ranges can support a flexible inflation targeting central bank in the short run. Erceg (2002) notes that trade-offs between inflation and other variables such as output volatility, plus a choice of a policy rule or loss function, generate a range for inflation. This approach sets upper limits for inflation volatility, while by contrast, our framework requires inflation to be frequently outside the band. Orphanides and Weiland (2000) consider a central bank that has a loss function that is flat around a point target, which generates a target range.

The strategy outlined in this paper also addresses the need for clearer central bank communications to help firms and households better understand and hence promote the effectiveness of monetary policy. Coibion, Gorodnichenko and Weber (2019) study how information about monetary policy is understood by the general public, and conclude that direct communications are most effective rather than relying on news media. Communicating in terms that are understandable to a general layperson can thus improve comprehension of monetary policy actions and improve expectations, since D'Acunto et al. (2019) highlight these as potential barriers to policy effectiveness. Orphanides (2019) discusses using monetary policy rules to improve communication in the US. Additionally, in a review of Federal Open Market Committee (FOMC) communications, Cecchetti and Schoenholtz (2019) point to simplifying public statements as a way to improve FOMC statements. Using a tolerance band with a projection can be simply communicated.

The remainder of the paper proceeds as follows. In Section 2 we review inflation targeting and communication strategies around the world. In Section 3 we present a simple Fisherian model of inflation determination, and show how a tolerance band and forecasts for inflation can be used to communicate rules. Section 4 shows how the communication strategy would have worked in practice in the United States, and illustrates how tolerance bands and forecasts can be used to generate a metric for evaluating deviations from the implicit policy rule. Section 5 concludes. Additional results and details are in the Appendices. 


\section{Inflation Targeting Around the World}

In this section, we review the conduct of inflation targeting around the world. This review indicates that the three ingredients we identify as being consistent with communicating a policy rule are rather close to how central banks conduct policy. First, we highlight that while a large number of countries have targets for inflation, they differ in whether they have tolerance bands or not. Coupling this fact with the widespread practice of producing inflation forecasts, we can conclude the method of communicating monetary policy rules that we highlight is only a slight modification of existing practice for many countries. We also note that inflation bands are already used as a means to evaluate central bank performance. After our review of central banks around the world, we discuss the experience of the Sveriges Riksbank with inflation tolerance bands as an illustrative example of the issues surrounding tolerance bands as a communication device.

\subsection{Inflation Targets, Tolerance Bands, and Forecasts}

Table 1 lists the countries with some form of an explicitly stated inflation target. Among these, about a third have single point targets, although these include some major economies such as the UK and US. Even among these countries that have an explicit single point target, some have supporting ranges that play a role in policy, such as the UK and Sweden. The remaining countries have some sort of tolerance band; a majority of bands have a specific midpoint (e.g. Canada's target of $2 \% \pm 1 \%$ ), while some specify a band without an explicit midpoint (e.g. Australia's target of $2 \%-3 \%$ ), and a few have one-sided bands with an inflation target that acts as an upper bound (Switzerland and the Euro area have targets of $<2 \%$ ).

The table therefore highlights disagreement about how to set inflation targets across the world, and prompts some concerns about how specifying point targets in addition to, or instead of, tolerance bands helps the performance and communication of monetary policy. In the cases without a band, there may be difficulty achieving a level of inflation that exactly hits the target, which might translate to difficulty communicating an implicit policy rule. In the cases of a band without a midpoint, there may be some uncertainty or confusion about where inflation will be in the long run; for example, the Reserve Bank of New Zealand explicitly introduced a midpoint to their range in 2012 to help anchor inflation expectations (McDermott and Williams, 2018). In addition, for those countries that set a band of some sort, the widths of the bands vary across 
Table 1: List of Inflation Targets Across Countries

\begin{tabular}{|c|c|c|c|c|c|c|c|}
\hline \multicolumn{2}{|l|}{ No Band } & \multicolumn{2}{|c|}{ Band w/ Midpoint } & \multicolumn{2}{|c|}{ Band w/o Midpoint } & \multicolumn{2}{|c|}{ Upper Bound } \\
\hline Bangladesh & 5.4 & Albania & $3 \pm 1$ & Australia & $2-3$ & Euro & $<2$ \\
\hline Belarus & 5 & Armenia & $4 \pm 1.5$ & Botswana & $3-6$ & Switz. & $<2$ \\
\hline China & 3 & Azerbaijan & $4 \pm 2$ & Eswatini & $3-7$ & Vietnam & $<4$ \\
\hline Congo & 7 & Brazil & $3.75 \pm 1.5$ & Israel & $1-3$ & & \\
\hline Gambia & 5 & Canada & $2 \pm 1$ & Jamaica & $4-6$ & & \\
\hline Georgia & 3 & Chile & $3 \pm 1$ & Kazak. & $4-6$ & & \\
\hline Iceland & 2.5 & Colombia & $3 \pm 1$ & Kyrgyzstan & $5-7$ & & \\
\hline Japan & 2 & Costa Rica & $3 \pm 1$ & Nigeria & $6-9$ & & \\
\hline Malawi & 5 & Czech Rep. & $2 \pm 1$ & S. Africa & $3-6$ & & \\
\hline Mozambique & 5.6 & Domin. Rep. & $4 \pm 1$ & Sri Lanka & $4-6$ & & \\
\hline Nepal & 6 & Egypt & $7 \pm 2$ & Thailand & $1-3$ & & \\
\hline Norway & 2 & Ghana & $8 \pm 2$ & Uruguay & $3-7$ & & \\
\hline Pakistan & 6 & Guatemala & $4 \pm 1$ & Zambia & $6-8$ & & \\
\hline Russia & 4 & Hungary & $3 \pm 1$ & & & & \\
\hline Samoa & 3 & Honduras & $4 \pm 1$ & & & & \\
\hline S. Korea & 2 & India & $4 \pm 2$ & & & & \\
\hline Sweden & 2 & Indonesia & $3 \pm 1$ & & & & \\
\hline Tanzania & 5 & Kenya & $5 \pm 2.5$ & & & & \\
\hline Tonga & 5 & Mexico & $3 \pm 1$ & & & & \\
\hline UK & 2 & Moldova & $5 \pm 1.5$ & & & & \\
\hline US & 2 & Mongolia & $6 \pm 2$ & & & & \\
\hline Uzbekistan & 5 & New Zealand & $2 \pm 1$ & & & & \\
\hline & & Paraguay & $4 \pm 2$ & & & & \\
\hline & & Peru & $2 \pm 1$ & & & & \\
\hline & & Philippines & $3 \pm 1$ & & & & \\
\hline & & Poland & $2.5 \pm 1$ & & & & \\
\hline & & Romania & $2.5 \pm 1$ & & & & \\
\hline & & Rawanda & $5 \pm 3$ & & & & \\
\hline & & Serbia & $3 \pm 1.5$ & & & & \\
\hline & & Tajikistan & $7 \pm 2$ & & & & \\
\hline & & Turkey & $5 \pm 2$ & & & & \\
\hline & & Uganda & $5 \pm 2$ & & & & \\
\hline & & Ukraine & $5 \pm 1$ & & & & \\
\hline & & W African S & $2 \pm 1$ & & & & \\
\hline
\end{tabular}

Note: List of inflation targets is for the year 2021 from Central Bank News (2021).

central banks, and this variation may signal something about the implicit policy rule. ${ }^{3}$ These bands vary between being expected upper bounds for the realizations of inflation, versus tighter

\footnotetext{
${ }^{3}$ Central banks are well aware of these trade-offs: for example, Banco Central Do Brasil (2016) notes that an inflation band cannot be too wide, since it could signal a lack of commitment to the inflation target, which implies an instrument rule that responds weakly when inflation deviates from target.
} 
ranges that reflect a desire to bring future inflation within a certain range. The communication strategy we discuss is more in line with the latter type of range, but a key take-away is that bands are widely used as part of inflation targeting frameworks.

Beyond the specification of inflation targets and tolerance bands, central banks widely produce forecasts of inflation and other key macroeconomic variables. The format of these forecasts can vary between model-based or subjective forecasts, and either be consensus forecasts or forecasts made by individual participants. Either way, the forecasts give an indication of the central bank's views on future economic conditions and policy, and thus indicate to some extent the implicit policy rule or reaction function used.

Finally, the inflation bands can be used as a metric for central bank performance; for example, while the U.K. has an official point target of $2 \%$, the Governor of the Bank of England writes a letter explaining any misses exceeding 1 percentage point. This procedure generates accountability for the Bank of England and implicitly sets a standard for deeming when policy has been successful or not.

In the following sections, we develop a framework where effective communication can take the place of explicitly declaring a monetary policy rule. The keys to the framework are a point target for inflation, a band around that objective, and forecasts. As noted, these ingredients are already key elements in the conduct of policy across the world-much more so than explicitly using policy rules. Despite the fact that the Sweden appears on the list of countries that have a point target, they currently have a variation band that is used to help communicate policy. Further, the Sveriges Riksbank has changed how it communicates policy several times, and these changes illustrate some of the issues with tolerance bands and forecasts. So before presenting the theoretical Fisherian and New Keynesian models, we first examine the Riksbank's experience in detail.

\subsection{The Sveriges Riksbank's Experience}

The Riksbank provides a useful example for understanding some of the issues central banks encounter regarding tolerance bands. In January 1993, they set a $2 \%$ inflation target expected to be achieved in 1995 and then remain in effect going forward. The target included a tolerance band of $+/-1 \%$. According to Heikensten (1999), the purpose of the band was to convey that deviations from the target are probable, but that the Riksbank had an intention of limiting such deviations. In May 2010, the Riksbank removed the tolerance bands for a few reasons. First, as

explained in Riksbank (2010), they believed that the public had sufficient understanding that 
monetary policy persistently faces uncertainty and unexpected events will cause inflation to deviate from its target. Second, the Riksbank communicated that deviations from target can be part of a deliberate strategy under a flexible inflation targeting framework, which places weight on achieving other objectives than only hitting the inflation target. These deviations can at times exceed the tolerance interval. Third, inflation expectations were viewed as well-anchored, so deviations from the target, or even outside the tolerance interval, were not seen as having a tangible effect on longer-term inflation expectations. Between 1995 and the time of eliminating the tolerance band, inflation was outside of the band about half of the time, but was not viewed as having any effect on the Riksbank credibility. In sum, the Riksbank viewed the tolerance band as "obsolete," as deviations outside of the tolerance band were viewed as a "natural part of monetary policy." Dropping the bands were also viewed as having no consequences for the "way in which monetary policy is conducted and communicated."

Later, the Riksbank revisited some of the costs and benefits of specifying a tolerance band (Riksbank, 2016). A band provides a signal that some variation around the target should be expected, though monetary policy will aim to limit such deviations; this rationale supported the original specification of the tolerance band in 1993. Monetary Policy Reports give detailed inflation forecasts, and a tolerance band could complement these forecasts by providing a "clearer alternative" of illustrating uncertainty around inflation. As a result, a band may aid in deflecting public criticism about the level of inflation, as long as it was running within the interval. Indeed, Andersson and Jonung (2017) note, rather than expecting that inflation might vary more than 1 percent from target, the external focus on the Riksbank achieving 2 percent became stronger: "Any deviation from this exact number was interpreted as a monetary policy failure. The debate became obsessed with the number 2.0, despite the fact that the Riksbank had never announced that the rate of inflation should be exactly at $2.0 \%$. The lack of an explicit band undermined the Riksbank's communication strategy and thus its credibility."

The Riksbank's experience thus presents a useful case study that highlights the fact that inflation targets, inflation bands, and forecasts can underpin an effective communication strategy. We now turn to our theoretical frameworks, a Fisherian model, that connects communication with policy rules.

\section{A Fisherian Model of Inflation}

In this section, we present a simple Fisherian model of inflation and monetary policy in order to highlight how central bank communication about bands and horizons can pin down a rule. We 
first consider a case with full information and derive results and implications, and then consider cases with imperfect information.

\subsection{Model Setup and Basic Results with Full Information}

The model is a simple Fisherian model of inflation determination. The log-linearized equation for pricing a bond that costs $\$ 1$ at time $t$ and pays out at a net interest rate of $i_{t}$ in $t+1$ is

$$
i_{t}=\mathbb{E}_{t}\left[\pi_{t+1}\right]+r_{t}
$$

where $\mathbb{E}_{t}\left[\pi_{t+1}\right]$ denotes the time $t$ expectation of inflation in the subsequent period, and $r_{t}$ denotes the equilibrium ex ante real interest rate. This real interest rate is taken to be an exogenous process given by

$$
r_{t}=\tau_{t}+\varepsilon_{t},
$$

where $\varepsilon_{t}$ is i.i.d. with mean zero, and $\tau_{t}$ is a persistent component that follows

$$
\tau_{t}=\rho \tau_{t-1}+\omega_{t}
$$

where $0 \leq \rho<1$ and $\omega_{t}$ is an i.i.d. mean-zero shock.

Monetary policy follows a simple Taylor rule given by

$$
i_{t}=\alpha \pi_{t}+\eta_{t}
$$

where $\alpha$ governs how responsive the nominal interest rate is to inflation, and $\eta_{t}$ denotes an i.i.d., mean zero monetary policy shock. Note that by log-linearizing around the appropriate steady state, we have already required a point inflation target for monetary policy.

In this simple setup, a rational expectations equilibrium requires the private sector to understand the monetary policy rule, and so we consider the case where policy follows a rule, and the monetary authority must communicate policy in a way that is consistent with and thus reinforces the rule. From that standpoint, communicating the current stance of policy $i_{t}$ is not enough to pin down the rule, as there are an infinite set of combinations of the policy rule parameter $\alpha$ and the monetary policy shock $\eta_{t}$ that can produce a given nominal interest rate. ${ }^{4}$

\footnotetext{
${ }^{4}$ Due to the endogeneity of current inflation, this argument can be seen a bit more clearly if lagged inflation is in the policy rule. In that case, conditional on $\pi_{t-1}$, there are clearly a infinite set of combinations of $\alpha$ and $\eta_{t}$ that produce a given $i_{t}$. We use current inflation because it greatly simplifies the remainder of the analysis.
} 
The central bank could communicate the policy rule directly, which would entail revealing its functional form, parameter values and discretionary component, $\eta$. However, Section 2 highlights that this is not how most central banks communicate, but instead prefer guidance about hitting an inflation target or moving inflation within some band, possibly over a specified time frame.

Assuming that households do possess all information about the policy rule leads to the unique solution to the Fisherian economy in equations (1), (2), and (4), given the Taylor principle $(\alpha \geq 1)$ holds, is

$$
\pi_{t}=\frac{1}{\alpha-\rho} \tau_{t}+\frac{1}{\alpha} \varepsilon_{t}-\frac{1}{\alpha} \eta_{t},
$$

which relates realized inflation to the persistent component of the real interest rate $\tau_{t}$, the transitory shock to the real rate $\varepsilon_{t}$, the monetary policy shock $\eta_{t}$, the monetary policy rule parameter $\alpha$, and features of the structural economy, which in this simple example are captured by the persistence of the real rate $\rho$. Given that the shocks $\varepsilon_{t}$ and $\eta_{t}$ are i.i.d., expected inflation is given by

$$
\mathbb{E}_{t}\left[\pi_{t+j}\right]=\frac{1}{\alpha-\rho} \rho^{j} \tau_{t} .
$$

This result highlights that, while current inflation depends upon the current real interest rate and monetary policy shocks, expected future inflation is only a function of the persistent component of the real rate.

If we now assume that the central bank only indicates it follows a rule that has the form of (4), but doesn't give a precise value for alpha or eta, effective communication can be achieved by providing providing a path of expected inflation consistent with (6). Communicating the path provides more than enough information for households and firms to back out the policy parameter $\alpha$.

An additional way of communicating policy instead of producing an entire path for expected inflation is to give a specific horizon and inflation objective. If, given a current value for the persistent component of the real rate $\tau_{t}$, the central bank states that it expects "inflation will be $\mu$ from the inflation target in $N_{t}$ periods," this statement implies

$$
\mu=\mathbb{E}_{t}\left[\pi_{t+N_{t}}\right]=\frac{1}{\alpha-\rho} \rho^{N_{t}} \tau_{t} .
$$

Two important results, are key on how to use this communication strategy and why it works to reveal the rule.

First, the inflation target cannot be hit with precision in finite time, so $\mu=0$ is impossible, 
as this implies $N_{t} \rightarrow \infty$ for all values of $\alpha$. Since the inflation target is a point target, communication about returning inflation to target in any time frame is infeasible. In other words, specifying a degree of tolerance $\mu$ around the inflation target is imperative.

Second, the reason a statement about a tolerance $\mu$ and a horizon $N_{t}$ is effective in communicating the policy rule is that equation (7) is invertible. Mathematically, after a realization $\tau_{t}$ and given $\mu$ and $N_{t}$, the private sector can recover the policy parameter through

$$
\alpha=\frac{\rho^{N_{t}} \tau_{t}}{\mu}+\rho .
$$

Further, the expected path of inflation in equation (6) can be put in terms of the tolerance $\mu$ and the horizon $N_{t}$, which now satisfies

$$
\mathbb{E}_{t}\left[\pi_{t+j}\right]=\rho^{j-N_{t}} \mu,
$$

and hence the communication uniquely pins down the expected path for inflation. In this simple Fisherian model, directly communicating the policy parameter is equivalent to communicating the tolerance $\mu$ and a horizon $N_{t}$ due to the unique mapping.

In addition, once the policy parameter $\alpha$ is pinned down through the effective communication of a band $\mu$ and horizon $N_{t}$, the current interest rate $i_{t}$ indirectly establishes the size of the monetary policy shock $\eta_{t}$. In this simple model, the forward-looking behavior of the economy implies that previous deviations from the rule are inconsequential for current and future economic outcomes. As a result, a comparison with ex ante stated horizons with ex post realized time frames is not informative about the degree of monetary policy deviation. We return to this issue in Section 4.

\subsection{Examples}

The mapping in equation (7) has intuitive implications for how changes in the policy parameter $\alpha$ produce different tolerances $\mu$ and horizons $N_{t}$. In particular, a higher $\alpha$ implies either a shorter horizon $N_{t}$ in order to hit a given tolerance $\mu$, or a lower tolerance $\mu$ associated with a given horizon $N_{t}$. Likewise, the inverse mapping in equation (8) also has straightforward implications for how changes in stated tolerances $\mu$ and horizons $N_{t}$ affect the implied policy parameter. Given a specified tolerance band $\mu$, then a desire to hit that band in a shorter time (lower $N_{t}$ ) necessarily implies a higher value of the policy parameter $\alpha$. Likewise, given a specific horizon $N_{t}$, then a desire to hit a smaller tolerance band (smaller $\mu$ ) requires a higher value of 
Figure 1: Impulse Responses in the Fisherian Model

(a) Inflation

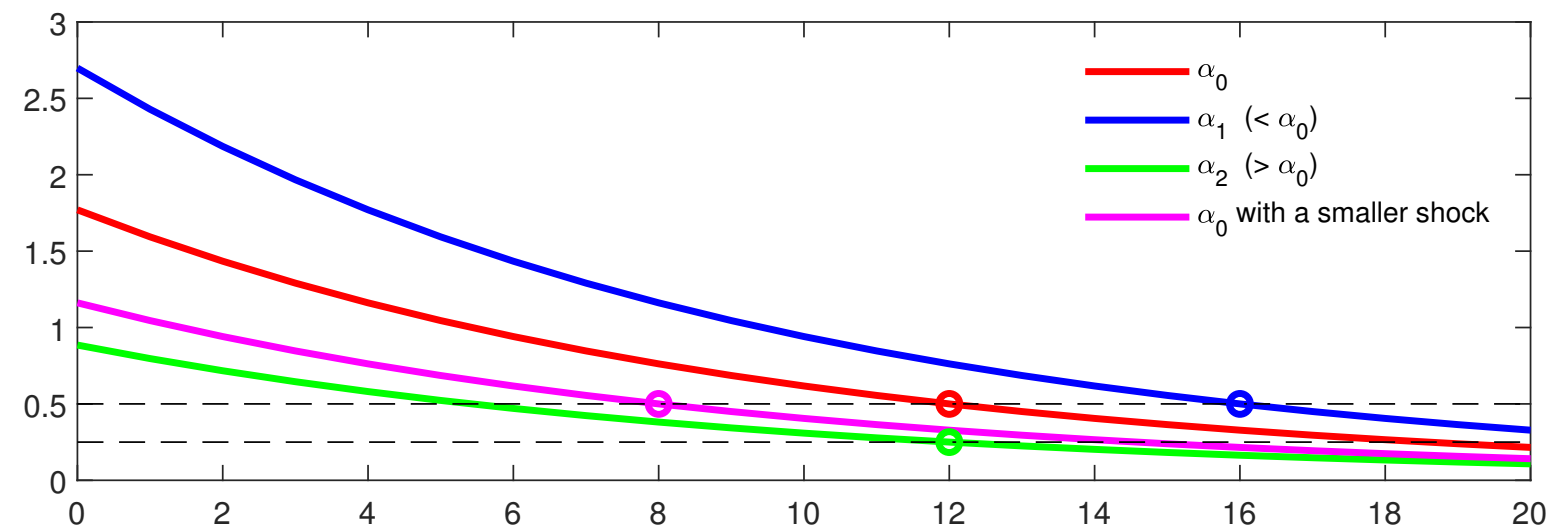

(b) Nominal Rate

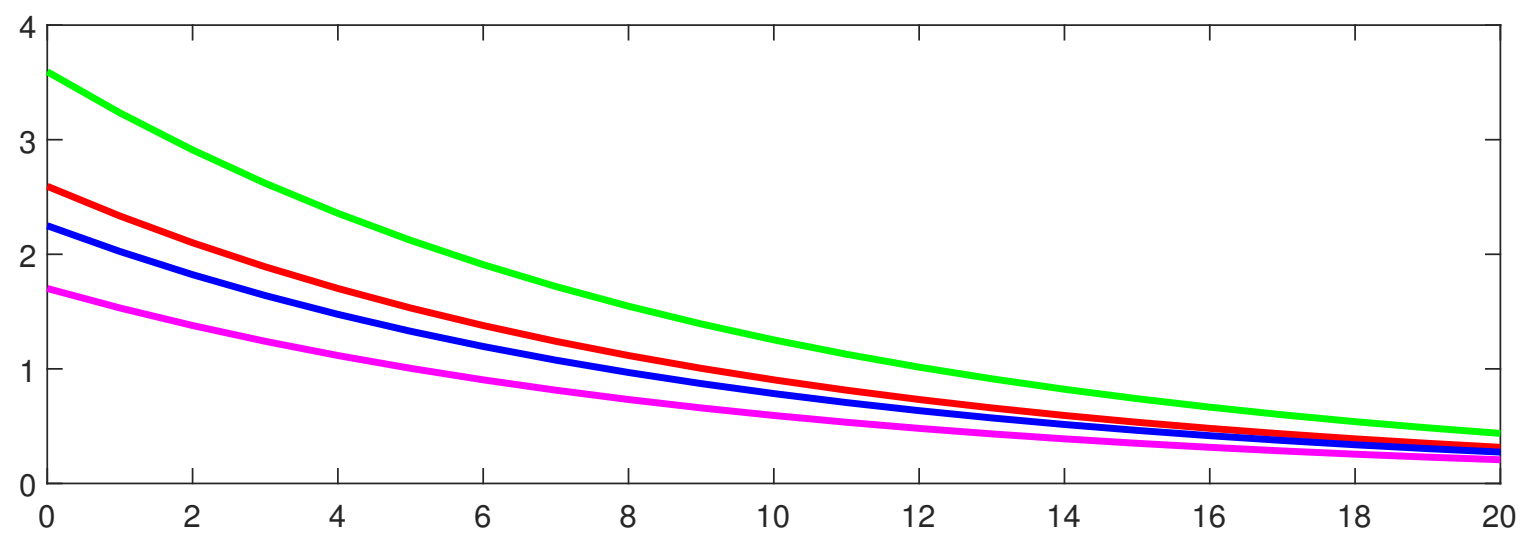

Note: Shows impulse responses to a $1 \mathrm{pp}$ shock $(0.66 \mathrm{pp}$ in the smaller shock case) to the real interest rate when $\rho=0.9$. Values for the policy parameters are $\alpha_{0}=1.46, \alpha_{1}=1.27$, and $\alpha_{0}=2.03$.

$\alpha$ as well.

Figure 1 shows how, given a value of $\rho$, for different policy parameters $\alpha$, the impulse response function of inflation to a real rate shock can be used to pin down the band $\mu$ and the horizon $N_{t}$. For example, after a shock to the real rate, a policy parameter of $\alpha_{0}$ can be communicated through a range of $\left(\mu, N_{t}\right)$ combinations given by the red line, but if the monetary authority has an inflation tolerance of $\mu=0.5$, then they can communicate the rule by saying "inflation will be 0.5 percentage points from the inflation target in 12 periods." Similarly, the central bank with a policy rule of $\alpha_{1}$ could state "inflation will be 50 percentage points from the inflation target in 16 periods," while one with $\alpha_{2}$ and a lower tolerance $\mu$ could state "inflation will be 0.25 percentage points from the inflation target in 12 periods." 
Figure 2: Effective Communication Pins Down the Policy Parameter in the Fisherian Model

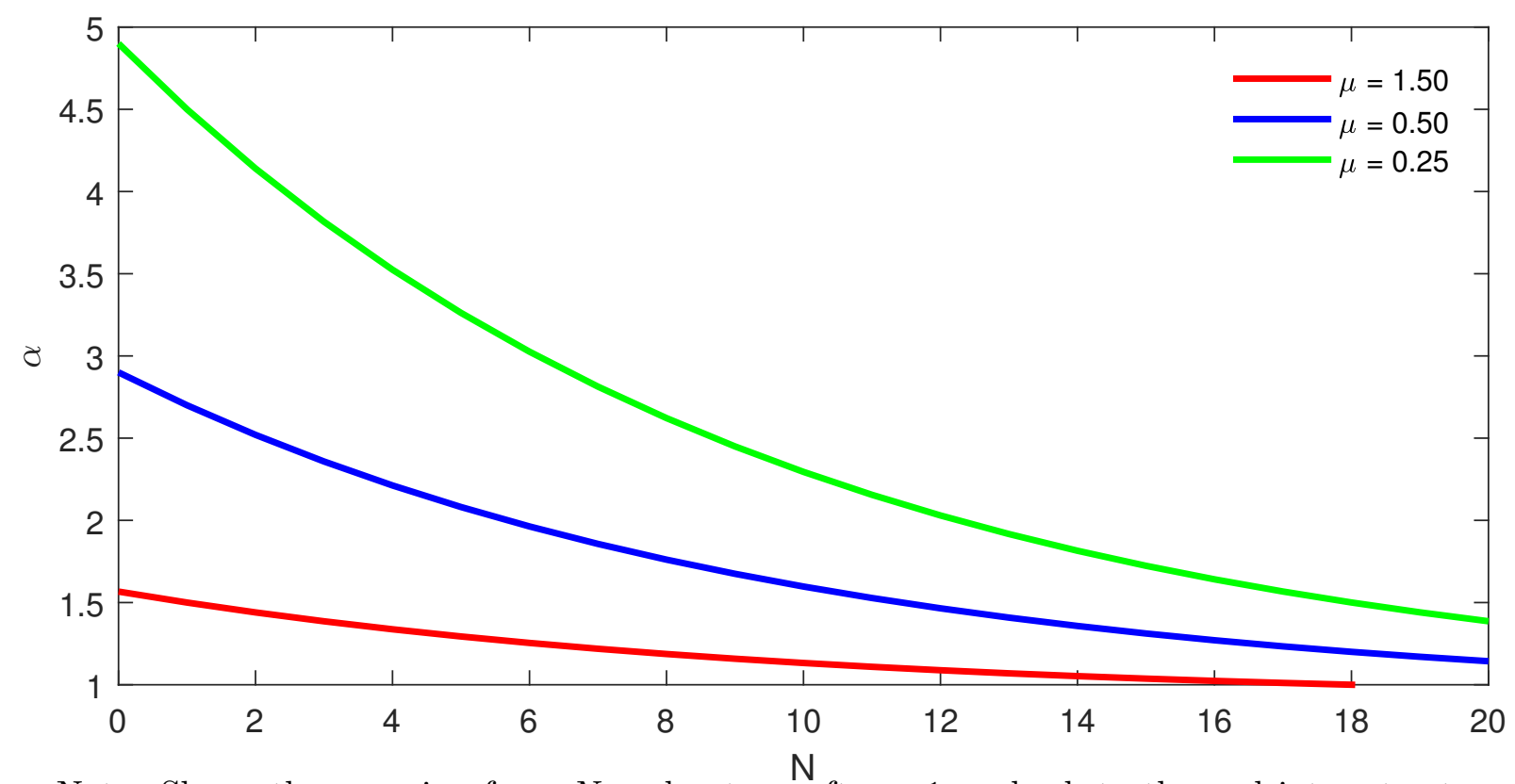

Note: Shows the mapping from $N$ and $\mu$ to $\alpha$ after a 1 pp shock to the real interest rate when $\rho=0.9$.

Using tolerance bands and horizons also provides flexibility to vary communication after shocks of various sizes. As noted, Figure 1 depicts a band of 0.5 percentage points and horizon 12 can be used to convey a policy parameter of $\alpha_{0}$ after a shock to the real rate. If instead, there is a smaller shock, then the same rule can be communicated by "inflation will be 0.5 percentage points from the inflation target in 8 periods." Thus, smaller shocks end up meeting the tolerance band in shorter time frames, while larger shocks extend the horizon.

The implications of Figure 1 for communication also highlight that given $\left(\mu, N_{t}\right)$, the communication can pin down the policy parameter $\alpha$. Figure 2 builds upon this example to show the inverse mapping in equation (8) by showing how a tolerance band $\mu$ and horizon $N_{t}$ imply a unique policy parameter $\alpha$. The curves show, given $\left(\mu, N_{t}\right)$, the implied $\alpha$ that achieves those objectives. The mapping is unique, and given $\mu$ a larger $N_{t}$ implies a lower $\alpha$ as monetary policy does not have to react as strongly to meet the horizon objective. Similarly, given a horizon $N_{t}$, if the band is smaller, meaning $\mu$ is lower, then $\alpha$ must be larger in order to bring inflation within the band in the given time frame. Importantly, given a band $\mu$, there are values of $N_{t}$ that imply $\alpha<1$, which generates indeterminacy; for example if $\mu=1.5$ then the maximum $N_{t}$ is 18 periods, and if the monetary authority communicates a longer horizon the implied equilibrium is non-unique. 
This simple Fisherian example thus highlights how a clearly articulated band for inflation and a horizon can be used in place of specifying an exact policy rule. Given these simple results, we now turn to a discussion of several implications for communication.

\subsection{Implications for Communication}

There are several important implications for how the inverse mapping between $\left(\mu, N_{t}\right)$ and $\alpha$ shown in equation (8) matters for communication of policy. These results highlight how vague communication or imprecision about the objectives of $\left(\mu, N_{t}\right)$ can lead to a rule with undetermined parameters.

First, if the communication is vague by stating "inflation will be close to the inflation target in $N_{t}$ periods," rather than specifying an exact tolerance, a range of values for $\alpha$ are possible. In this case, if close is interpreted as possibly a range of tolerances $\mu \in[\underline{\mu}, \bar{\mu}]$, then the range of possible policy parameters is given by

$$
\alpha \in\left[\frac{\rho^{N_{t}} r_{t}}{\bar{\mu}}+\rho, \frac{\rho^{N_{t}} r_{t}}{\underline{\mu}}+\rho\right] .
$$

For example, if $N_{t}=12$, then Figure 1 shows that if $\mu \in[0.25,0.50]$, then $\alpha \in\left[\alpha_{0}, \alpha_{2}\right]$.

Second, as a range of tolerances produces a range of possible policy parameters, so does a range of horizons. Even if a band around the target is specified, if a range of horizons is vague by stating "inflation will be $\mu$ of the inflation target over the medium term" and the phrase medium term is interpreted as a range of horizons $N_{t} \in[\underline{N}, \bar{N}]$, then the range of possible policy parameters is

$$
\alpha \in\left[\frac{\rho^{\overline{N_{t}}} r_{t}}{\mu}+\rho, \frac{\rho^{\underline{N}} r_{t}}{\mu}+\rho\right]
$$

For example, if $\mu=0.50$, then the top panel of Figure 1 shows that if $N_{t} \in[12,16]$, then $\alpha \in\left[\alpha_{1}, \alpha_{0}\right]$.

Third, given a fixed band $\mu$ and horizon $N_{t}$, the mapping to policy parameters $\alpha$ is still dependent on $\rho$. As a result, if there is structural change in the economy-incorporated by possibly a different value of $\rho$ in this economy-then the mapping from $\left(\mu, N_{t}\right)$ to $\alpha$ will change as well. From this perspective, given a constant statement about the band and horizon, the policy parameter must adjust given any changes in $\rho$.

Fourth, while in principle the band can be time-varying along with the horizon, more straightforward communication would leave one of these two features fixed to ensure consistency and 
eliminate a degree of freedom in communication. This feature reflects how, as shown in Table 1, central banks pick constant bands for their inflation targets in practice.

This simple Fisherian model has therefore provided some clear implications for communicating monetary policy rules. However, the assumption of perfect information about the sources of shocks might be too restrictive. We next consider the implications of imperfect information in this environment.

\subsection{Communication Under Imperfect Information and Disagreement}

One aspect of the results above is the full information assumption that households and the central bank can perfectly separate the persistent and transitory components driving the real rate. This assumption leads to a common information set and inference about the economy between households and the central bank so that communication can effectively convey a rule. Information frictions can play an important role in how expectations are formed (Coibion and Gorodnichenko, 2015), and may be especially dependent upon cognitive abilities (DAcunto et al., 2019), or when price changes are more salient due to the frequency of purchases (D'Acunto et al., 2021; DAcunto, Malmendier and Weber, 2021). To show the limits of communication while maintaining a tractable framework, we consider an environment with imperfect information based on a filtering problem.

\subsubsection{Imperfect Information}

Specifically, we modify the setting so only the real rate $r_{t}$ is observable and the structural parameter $\rho$ is known, but the underlying components $\tau_{t}$ and $\omega_{t}$ are not observed. When the real rate $r_{t}$ is observed, the relative importance of the two components must be inferred. Assuming normality of the errors, the Kalman filter applies to the filtering problem.

Thus, assume households solve a filtering problem where they carry the prediction of the real rate prior to its realization $r_{t \mid t-1}=\tau_{t \mid t-1}$, where $i \mid j$ reflects the Kalman filter notation denoting the expectation of the variable at time $i$ given the information set at time $j$. Consequently, the evolution of the persistent component implies $\tau_{t \mid t-1}=\rho \tau_{t-1 \mid t-1}$, which yields a surprise $a_{t}=r_{t}-r_{t \mid t-1}$ and leads households to update their view according to

$$
\tau_{t \mid t}=\tau_{t \mid t-1}+K a_{t}
$$

where $K=\sigma_{\omega}^{2} /\left(\sigma_{\omega}^{2}+\sigma_{\varepsilon}^{2}\right)$ denotes the steady state Kalman gain. If households perceive shocks to 
$a_{t}$ as relatively large and carrying signal about future real rates, then this perception translates to a larger impact to inflation that increases with its persistence (i.e. $\rho$ ).

Combining the filtering problem with the Fisherian equation (1) and the policy rule (4), ${ }^{5}$ inflation evolves according to

$$
\pi_{t}=\frac{1}{\alpha-\rho} \tau_{t \mid t-1}+\left[\frac{1}{\alpha-\rho} \frac{\rho}{\alpha} K+\frac{1}{\alpha}\right] a_{t} .
$$

This equation shows that inflation evolves depending on the previous period's forecast of the persistent component, as well as the surprise in the real rate relative to its expectation.

In this case, any future surprises are unexpected, so inflation expectations are given by

$$
\mathbb{E}_{t}\left[\pi_{t+j}\right]=\frac{1}{\alpha-\rho} \rho^{j} \tau_{t \mid t-1}
$$

Importantly, inflation expectations depend on the perceived persistent state in the same way as they rely on the true state when it is known, as shown in in equation (7). Thus, as long as the household and central bank have the same perceived persistent state, then central banks can still provide a $\left(\mu, N_{t}\right)$ communication package that states inflation will be $\mu$ in $N_{t}$ periods that will allow households to identify $\alpha$. In other words, even if information is imperfect, communication will reveal the policy rule as in the full information case, and hence the results and implications will continue to hold.

\subsubsection{Central Bank and Household Disagreement}

A possible problem for communication comes if households and the central bank hold different views regarding the underlying state variable. Such circumstances arise if central banks imperfectly observe households views of the economy, if households and the central bank have differing Kalman gains attached to their forecasting errors on the real rate, or if the central bank has a more accurate inference about the state.

Differing Kalman gains can arise if either the central bank or household perceive the relative variances of the transitory shocks to the real rate or shock to its persistent component to be time varying, such as a UC-SV specification. Households and the central bank can certainly diverge regarding their views on relative variances and in practice, face an information gap in how to communicate these differences. Consequently, each will make a different inference on the underlying state, even if there is agreement on $\rho$ governing the persistent component.

\footnotetext{
${ }^{5}$ In the following, we abstract from the policy shock $\eta_{t}$ for simplicity.
} 
Even though there is an information gap, we assume the central bank is credible so that households and the central bank's forecasts must align. Thus, given a communication package of $\left(\mu, N_{t}\right)$, it follows from equation (14) that we can set the inflation forecasts of each equal at time $N_{t}$,

$$
\mu=\frac{1}{\alpha^{C B}-\rho} \rho^{N_{t}} \tau_{t \mid t-1}^{C B}=\frac{1}{\alpha^{H H}-\rho} \rho^{N_{t}} \tau_{t \mid t-1}^{H H}
$$

where $\alpha^{C B}$ is the policy rule the central bank intends to communicate based on its inference of the state $\tau_{t \mid t-1}^{C B}$, but households infer $\alpha^{H H}$ based on its inference of $\tau_{t \mid t-1}^{H H}$. Straightforward algebra then leads to

$$
\frac{\tau_{t \mid t-1}^{H H}}{\tau_{t \mid t-1}^{C B}}=\frac{\alpha^{H H}-\rho}{\alpha^{C B}-\rho}
$$

The implication of this disagreement is immediately evident. For example, if $\tau_{t \mid t-1}^{H H}>\tau_{t \mid t-1}^{C B}$, households will infer a more aggressive policy, $\alpha^{H H}>\alpha^{C B}$ than the central bank intends to implement. In equilibrium, households will be persistently surprised by high inflation, but attribute the upside surprises to transitory shocks to the real rate and not a weaker monetary policy response than they inferred from the central bank's communication. The converse also holds, so in this simple setup, the central banks understanding of the private sector's views on the current state of the economy is key in providing accurate communication about its policy rule. To the extent that there is an "information effect" of monetary policy where the private sector infers something about the central bank's beliefs about the state of the economy from policy actions, central banks need to take steps to infer private sector views on the state of the economy and then set policy based on those views. ${ }^{6}$

\section{Communicating Rules in Practice}

In this section, we consider a counterfactual history of monetary policy in the United States to illustrate how communicating bands and a horizon could potentially work in practice. We first introduce a hybrid New Keynesian model where inflation and the output gap are jointly determined and have both forward and backward looking behavior to generate rich dynamics.

\footnotetext{
${ }^{6}$ See Romer and Romer (2000) and Nakamura and Steinsson (2018) for evidence for an information effect, and Bauer and Swanson (2020) evidence against it. Tang (2015) and Jia (2019) study how to adapt optimal policy to when an information effect exists. In addition, the communication strategy we study might affect the extent of any information effect, since the message, medium, and messenger matter for the extent to which ordinary consumers incorporate the information coming from the central bank into their own subjective macroeconomic expectations (Coibion, Gorodnichenko and Weber, 2019; D'Acunto et al., 2020; DAcunto, Fuster and Weber, 2021).
} 
Then we use this model to consider monetary policy in the US and how a inflation targeting rule could have been communicated using a tolerance band and a horizon. Finally we highlight how the communication strategy naturally generates a metric for central bank performance.

\subsection{A Hybrid New Keynesian Model}

We consider a hybrid New Keynesian model with backward and forward looking components, based on the estimated model of Linde (2005). ${ }^{7}$ The model consists of a hybrid Phillips Curve that incorporates backward looking price-setting behavior,

$$
\pi_{t}=\theta \mathbb{E}_{t} \pi_{t+1}+(1-\theta) \pi_{t-1}+\kappa y_{t}+\varepsilon_{\pi, t}
$$

and an aggregate IS curve with multiple lags,

$$
x_{t}=\beta_{f} \mathbb{E}_{t} x_{t+1}+\left(1-\beta_{f}\right) \sum_{j=1}^{4} \beta_{y, j} x_{t-j}-\beta_{r}\left(i_{t}-\mathbb{E}_{t} \pi_{t+1}\right)+\varepsilon_{y, t}
$$

where $x_{t}$ denotes the output gap. Using the estimates of Linde (2005), we set $\theta=0.282$, $\kappa=0.048, \beta_{f}=0.430, \beta_{1}=1.275, \beta_{2}=-0.253, \beta_{3}=0.0012, \beta_{4}=-0.034$, and $\beta_{r}=0.087$. For the conduct of monetary policy, we study a policy rule that responds to inflation over the last four quarters,

$$
i_{t}=\alpha \sum_{j=0}^{3} \pi_{t-j}+\varepsilon_{r, t}
$$

We use data on inflation, the output gap, and interest rates to discipline the model and hence conduct of monetary policy. The series are from 1994-2019 and are shown in Figure $3 .{ }^{8}$ Inflation is both the quarter-over-quarter percent change in the Personal Consumption Expenditures Price Index, and the year-over-year percent change; the former is relevant for pricing behavior and the latter for the conduct of monetary policy. As in Linde (2005), the output gap is deviations in per capita real Gross Domestic Product from a quadratic trend. For the nominal interest rate, we use the federal funds rate until 2008, and the shadow rate of Wu and Xia (2016) thereafter. The use of the shadow rate allows us to consider a linear framework that abstracts from the zero lower bound, forward guidance, and asset purchases, all of which have been important features

\footnotetext{
${ }^{7}$ In Appendix A, we extend the results in Section 3 to a forward-looking New Keynesian model and consider alternative policy rule specifications.

${ }^{8}$ We use this sample period since monetary policy can be thought of as reasonably stable over this period, even though an official inflation target wasn't adopted until 2012.
} 
Figure 3: Inflation, Output Gap, and Nominal Rates in the Hybrid New Keynesian Model

(a) Inflation, Percent Annualized

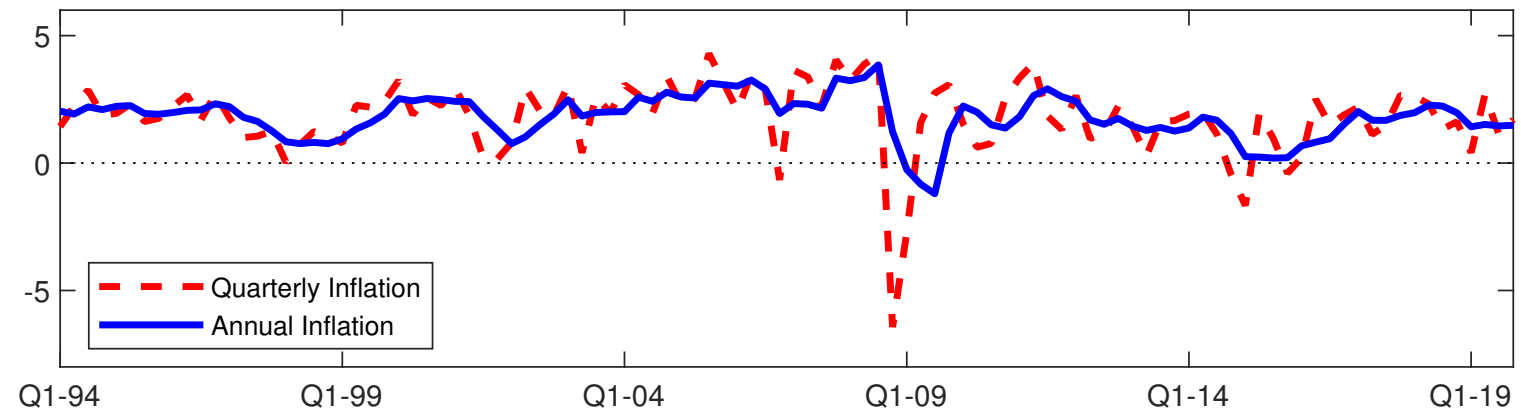

(b) Output Gap, Percent

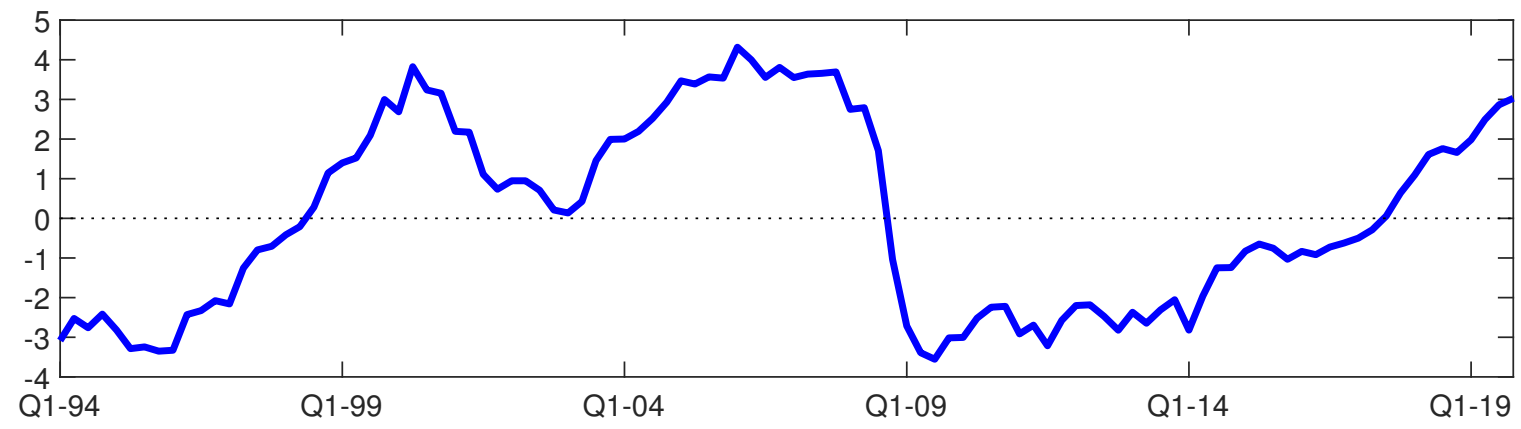

(c) Nominal Rate, Percent Annualized

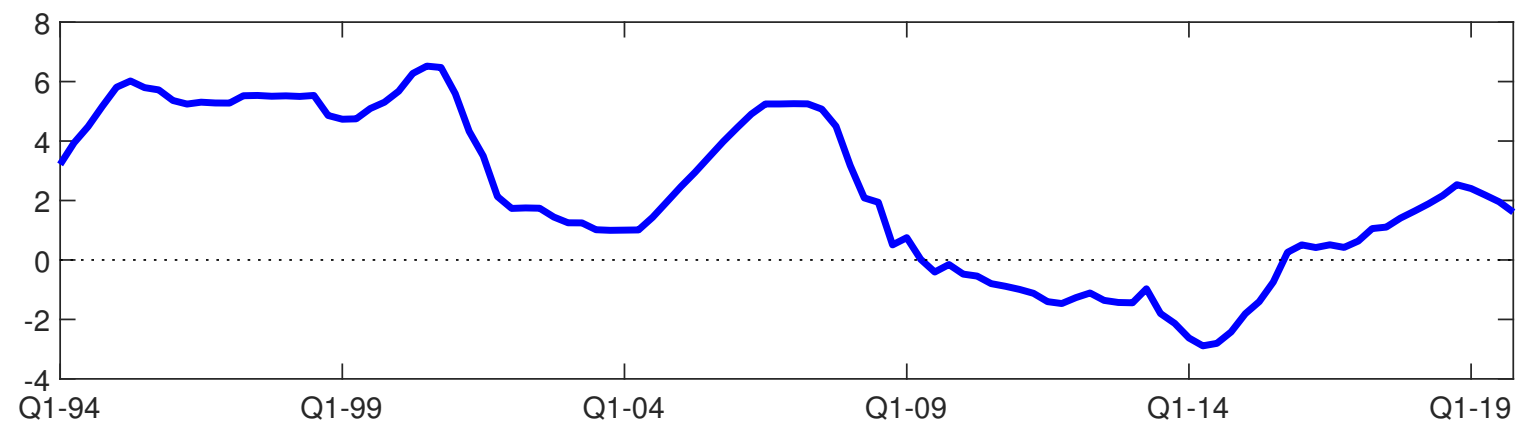

of monetary policy. The shadow rate effectively lets the nominal rate go below zero and capture the additional accommodation from unconventional measures; if we instead imposed the zero lower bound in our model without a richer model that included the effects of forward guidance and asset purchases, it would appear that monetary policy was tighter in the model than in actuality. 
Figure 4: Communicating Policy Rules with Bands and Horizons

(a) Annual Inflation, Deviations from Target with a 0.25 Percent Tolerance Band

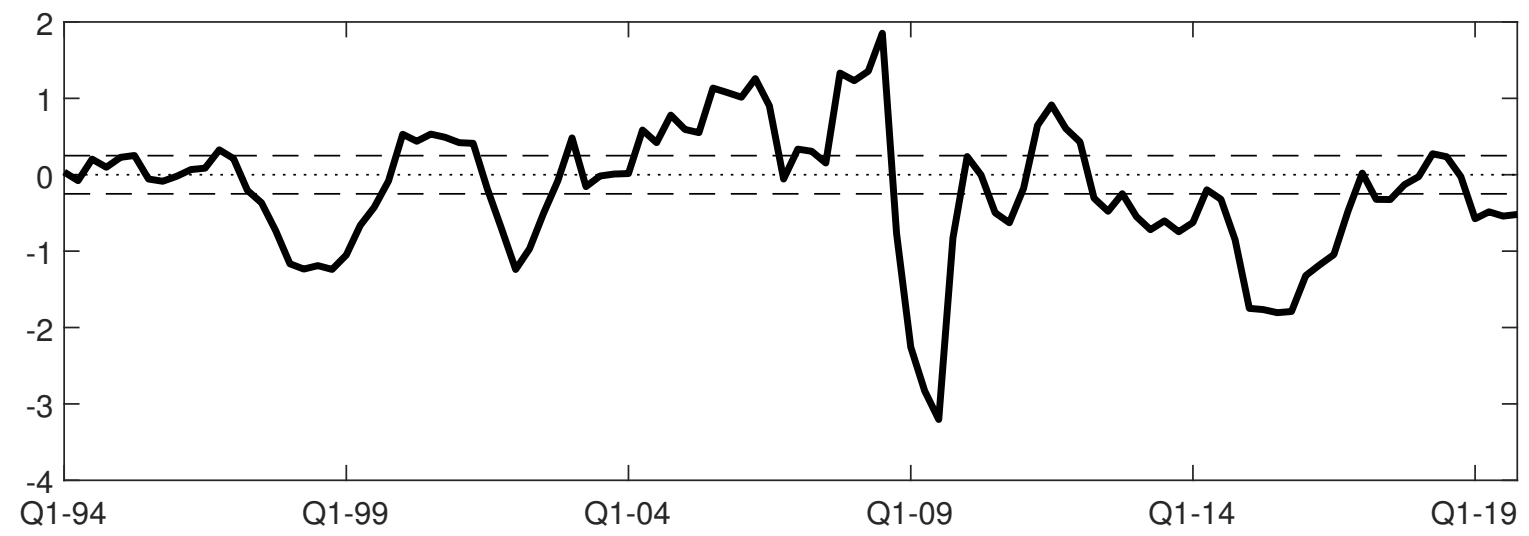

(b) Communicated Horizon for Return to Tolerance Band

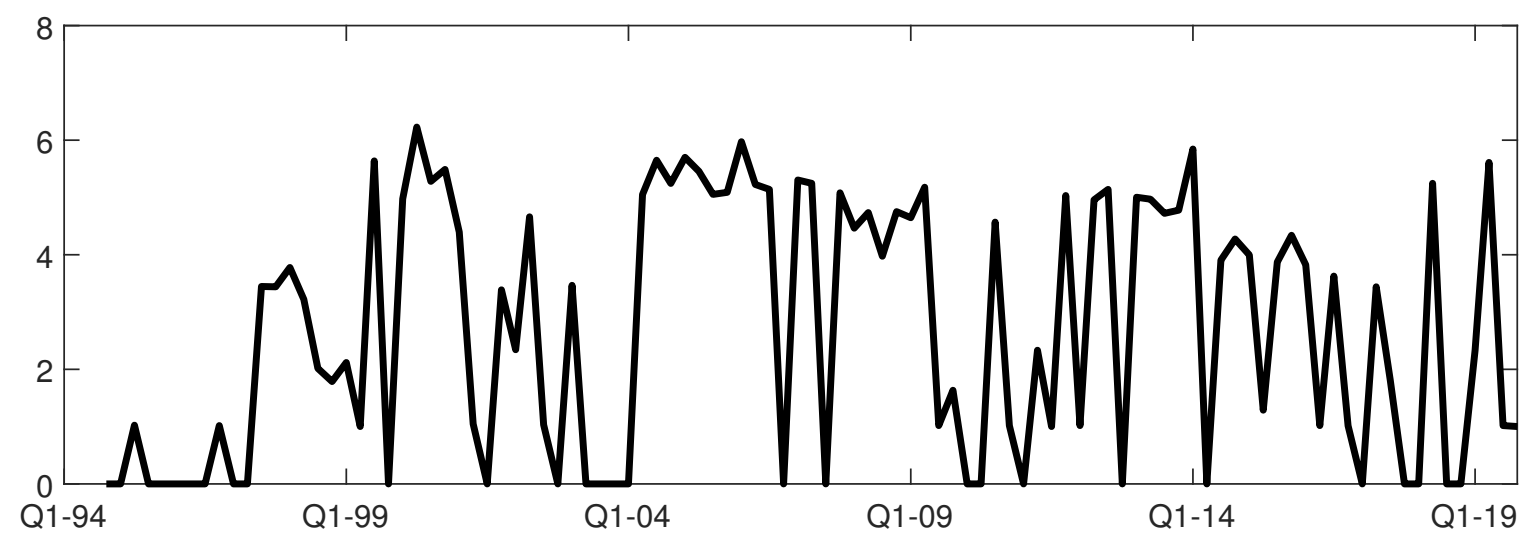

\subsection{Communicating a Rule}

To illustrate how our communication strategy would have worked in practice, we proceed in two steps. First, given the model and parameter values governing the Phillips and I-S curves, we pick a value of the policy parameter $\alpha=1 .^{9}$ Note that any policy parameter $\alpha$ can be rationalized, as different policy rules would imply different shocks; as we show, our choice closely aligns communications with outcomes. Second, given the evolution of inflation, the output gap, and the nominal rate, we determine the communication strategy of a band $\mu$ and horizon $N_{t}$ that conveys the policy parameter at each point in time. We assume a 2 percent inflation target, and choose a tolerance band of $\mu=0.25$ for this example.

Figure 4 shows results on how the policy rule parameter $\alpha$ could have been communicated

\footnotetext{
${ }^{9}$ Recall our rule targets annual inflation. This parameterization delivers a determinate equilibrium.
} 
using a band and horizon. The top panel shows the annual inflation deviations from a 2 percent target, along with a tolerance band of 0.25 percent. The figure clearly shows that inflation is outside the band a majority of the time, does indeed spend some portion of the time inside the band, and with both positive and negative deviations. For example, during the middle years of the sample, inflation was consistently higher than the band; later in the sample inflation tended to be below the band with higher frequency.

The lower panel of Figure 4 shows how communication would have worked in this context (see Appendix B for derivations). In this case, we assume that monetary policy uses $\alpha=1$, but also has policy shocks that lead to the nominal rate seen in Figure 3. Then, every period, policy is communicated by stating the nominal rate and "inflation will be $\mu=0.25$ percent from the inflation target in $N_{t}$ periods," where the lower panel plots $N_{t}$. These stated horizons vary with the current and previous level of inflation, as well as the current and lagged output gap, since general equilibrium interactions between pricing and output affect future inflation dynamics. For the most part, the horizon is under 6 quarters, as the response to inflation plus the implied internal dynamics of the economy tend to lead to relatively quick forecasted return of inflation to within the tolerance band.

\subsection{Metrics for Central Bank Performance}

The communication strategy of giving a horizon in which inflation is expected to return to the tolerance band produces a natural metric for evaluating central bank performance. By comparing the forecasted horizon with the ex post realized horizon, the central bank's adherence of the rule can be measured in a way that is both consistent with communications and related to outcomes rather than instruments.

Figure 5 shows how these metrics would apply in the historical context that we consider. The top panel shows the ex post realized horizon for returning to the band. In other words, it shows for each quarter in the sample, the actual number of periods until inflation actually returned to within $\mu=0.25$ percent of the inflation target. The chart shows variation in the actual horizon, with some horizons that were only a quarter or two, and two as long as 10 quarters.

The lower panel of Figure 5 is the key metric of central bank performance. It shows, for each quarter, the difference between the communicated horizon at that time (Figure 4b) with the actual horizon (Figure 5a). If the central bank perfectly followed a rule with no deviations, and the economy was subject to no future structural shocks, these two horizons would coincide and the discrepancy would be zero. When the discrepancy is negative, a combination of structural 
Figure 5: Central Bank Metrics

(a) Realized Horizon for Returning to Band

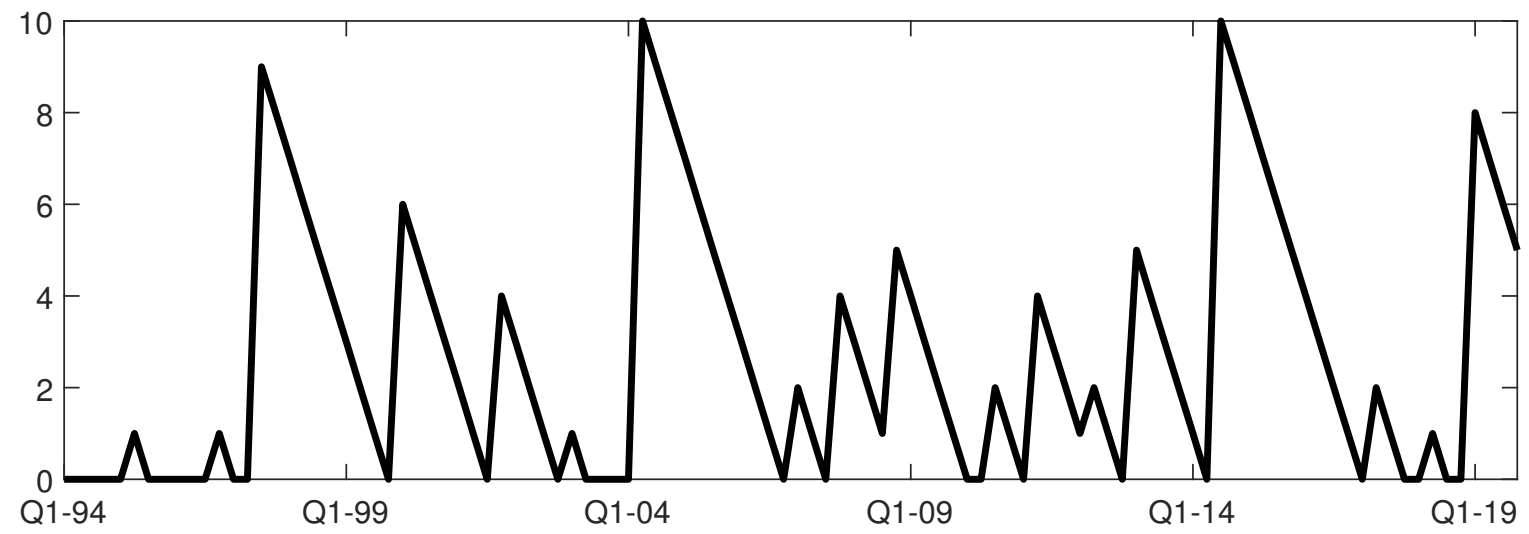

(b) Discrepancy between Stated and Realized Horizon

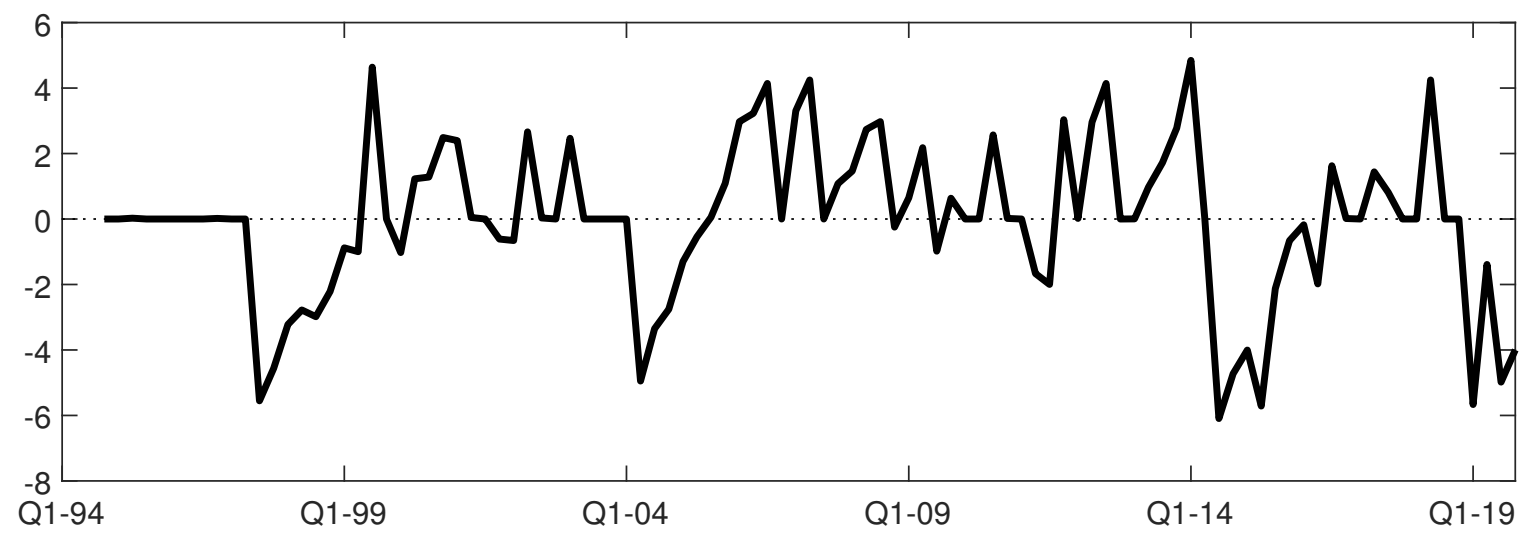

shocks and policy deviations led the actual horizon to be longer than the communicated one; in other words, it took longer than expected for inflation to return to within the tolerance band. Conversely, when the discrepancy is positive, the actual horizon is shorter than the communicated one, meaning it took shorter than expected for inflation to return to the tolerance band.

The presence of structural shocks means that, in general, the communicated and realized horizons will not always coincide. A full metric for central bank performance, then, would then look at discrepancies over a longer time span rather than focus on a particular episode. To illustrate this point, Figure 6 show the discrepancies for the baseline measure of $\alpha$ that we have studied, with an alternative higher $\alpha$. In the latter case, we assume the actual setting of rates remains unchanged, but instead the higher reaction parameter implies larger deviations from the systematic portion of the rule. 
Figure 6: Measuring Deviations, Central Bank Metrics

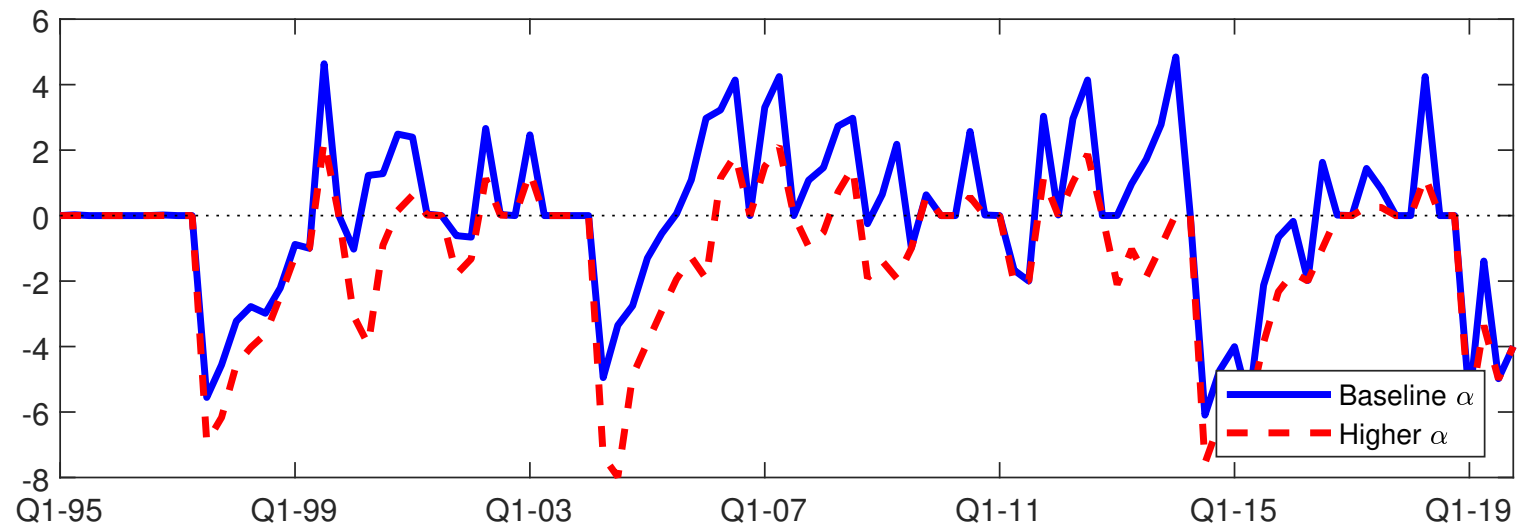

Comparing the deviations for the two different policy parameters shows how metrics that look at systematic discrepancies can help measure adherence to a rule. Relative to the lower value of $\alpha$, the more aggressive policy rule will tend to have more accommodative policy shocks; in other words, the interest rate tends to systematically set less aggressively than inflation alone would dictate. As a result, the discrepancies are consistently lower or more negative in this case. This result implies that the realized horizon ends up being longer than the communicated one. Thus, one could conclude by looking at these discrepancies that policy has tended to be characterized by relatively weaker responses than the rule intends.

As noted in Section 2, central banks around the world state policy in terms of forecasts rather than deviations from a rule. The communication strategy of tolerance bands and a horizon allows deviations to be communicated by changing the forecast of when inflation will hit the tolerance band, which puts communication in terms of the easily understood time dimension, and in the space of goals rather than instruments. If the monetary authority is on average more accommodative than its implicit rule, the horizons will tend to lengthen if inflation is above the band. Further, frequent or large deviations will drive a wedge between communicated horizons and realized outcomes, whereas infrequent or small deviations will imply horizons and outcomes are closely aligned. In these examples, the mean deviation for the baseline case is essentially zero, so expected and actual horizons align on average. By contrast, the mean deviation for the higher $\alpha$ case is -1.2 , meaning on average the actual horizon is about 4 months longer than the expected horizon.

In this way, the communication of rules via bands and horizons creates a metric with which to evaluate central bank performance and adherence to a rule. Lastly, we note that, in principle, the entire horizon of forecasts can be used to evaluate performance. However, using the 
communication strategy here simplifies the metric significantly, which is a key consideration for transparency.

\section{Conclusion}

Motivated by the wide-ranging communication strategies of the central banks around the world that use some form of inflation targeting, we develop a link between rules-based monetary policy and effective communication. Our framework relies on three key features: the specification of a point inflation target, tolerance bands around the point, and economic projections. In a simple Fisherian model, we show that effective communication about the band and a horizon for achieving that band given shocks can implicitly pin down a rule without having to explicitly express one. In addition, the results from a counterfactual history of the United States demonstrate that communicating rules in this way generates a metric with which to evaluate deviations from the implicit rule by comparing communication with realized outcomes. Central banks that use this communication can then reap the benefits of rules-based policy without necessarily having to codify their rule. 


\section{References}

Andersson, Fredrik and Lars Jonung. 2017. "Inflation Targets and the Benefits of an Explicit Tolerance Band." Vox EU. May 8.

Banco Central Do Brasil. 2016. "Inflation Targeting Regime in Brazil." Frequently Asked Questions Series.

Battini, Nicoletta and Edward Nelson. 2001. "Optimal Horizons for Inflation Targeting." Journal of Economic Dynamics and Control 21:891-910.

Bauer, Michael D and Eric T. Swanson. 2020. An Alternative Explanation for the Fed Information Effect. Working Paper 2020-06 Federal Reserve Bank of San Francisco.

Bernanke, Ben and Frederic Mishkin. 1997. "Inflation Targeting: A New Framework for Monetary Policy?" Journal of Economic Perspectives 11(2):97-116.

Cecchetti, Stephen G. and Kermit L. Schoenholtz. 2019. "Improving U.S. Monetary Policy Communications." Mimeo.

Central Bank News. 2021. "Inflation Targets Table for 2021." http://www. centralbanknews . info/p/inflation-targets.html. Accessed February 17, 2021.

Choi, Jason and Andrew Foerster. 2019. Optimal Monetary Policy Regime Switches. Working Paper 2019-3 Federal Reserve Bank of San Francisco.

Cochrane, John and John Taylor, eds. 2016. Central Bank Governance and Oversight Reform. The Hoover Institution.

Coibion, O. and Y. Gorodnichenko. 2015. "Information Rigidity and the Expectations Formation Process: A Simple Framework and New Facts." American Economic Review 105(8):2644-2678.

Coibion, Olivier, Yuriy Gorodnichenko and Michael Weber. 2019. Monetary Policy Communications and their Effects on Household Inflation Expectations. Working Papers 25482 NBER.

D’Acunto, F., U. Malmendier, J. Ospina and M. Weber. 2021. "Exposure to Grocery Prices and Inflation Expectations." Journal of Political Economy 129(5):1615-1639.

D’Acunto, Francesco, Daniel Hoang, Maritta Paloviita and Michael Weber. 2019. Human frictions in the transmission of economic policy. Working Paper Series in Economics 128 Karlsruhe Institute of Technology (KIT), Department of Economics and Business Engineering. 
D’Acunto, Francesco, Daniel Hoang, Maritta Paloviita and Michael Weber. 2020. Effective Policy Communication: Targets versus Instruments. Working Paper 2020-148 Becker Friedman Institute for Research In Economics.

DAcunto, Francesco, Andreas Fuster and Michael Weber. 2021. Diverse Policy Committees Can Reach Underrepresented Groups. Working Paper 29275 NBER.

DAcunto, Francesco, Daniel Hoang, Maritta Paloviita and Michael Weber. 2019. IQ, Expectations, and Choice. Working Paper 25496 NBER.

DAcunto, Francesco, Ulrike Malmendier and Michael Weber. 2021. "Gender Roles Produce Divergent Economic Expectations." Proceedings of the National Academy of Sciences 118(21):e2008534118.

Erceg, Christopher. 2002. "The Choice of an Inflation Target Range in a Small Open Economy." American Economic Review 92(2):85-89.

Fuhrer, Jeffrey C., Giovanni P. Olivei, Eric S. Rosengren and Geoffrey M. B. Tootell. 2018. Should the Fed Regularly Evaluate its Monetary Policy Framework? Working Papers 18-8 Federal Reserve Bank of Boston.

Heikensten, Lars. 1999. "The Riksbank's Inflation Target - Clarification and Evaluation." Sveriges Riksbank Quarterly Review 1999(1):5-17.

Ikeda, Daisuke and Takushi Kurozumi. 2014. Post-Crisis Slow Recovery and Monetary Policy. IMES Discussion Paper Series 14-E-16 Institute for Monetary and Economic Studies, Bank of Japan.

Jia, Chengcheng. 2019. The Informational Effect of Monetary Policy and the Case for Policy Commitment. Working Paper 19-07 Federal Reserve Bank of Cleveland.

Linde, Jesper. 2005. "Estimating New-Keynesian Phillips Curves: A Full Information Maximum Likelihood Approach." Journal of Monetary Economics 52(6):1135-1149.

McDermott, John and Rebecca Williams. 2018. "Inflation Targeting in New Zealand: An Experience in Evolution." Speech delivered to the Reserve Bank of Australia conference on central bank frameworks. April 12. 
Mishkin, Frederic S. and Niklas J. Westelius. 2008. "Inflation Band Targeting and Optimal Inflation Contracts." Journal of Money, Credit and Banking 40(4):557-582.

Nakamura, Emi and Jn Steinsson. 2018. "High-Frequency Identification of Monetary NonNeutrality: The Information Effect." The Quarterly Journal of Economics 133(3):12831330.

Orphanides, Athanasios. 2019. "Monetary Policy Strategy and its Communication." Mimeo.

Orphanides, Athanasios and Volker Weiland. 2000. "Inflation Zone Targeting." European Economic Review 44(7):1351-1387.

Riksbank. 2010. "The Riksbank Removes the Tolerance Interval from its Specified Monetary Policy Target." Monetary Policy Department. Decision - 31 May 2010.

Riksbank. 2016. "The Riksbank's Inflation Target - Target Variable and Interval." Riksbank Studies.

Romer, Christina D and David H Romer. 2000. "Federal Reserve Information and the Behavior of Interest Rates." American Economic Review 90(3):429457.

Schmitt-Grohe, Stephanie and Martin Uribe. 2007. "Optimal Simple and Implementable Monetary and Fiscal Rules." Journal of Monetary Economics 54(6):1702-1725.

Smets, Frank. 2000. "What Horizon for Price Stability." European Central Bank Working Paper No. 24.

Svensson, Lars E. O. 1999. "Inflation Targeting as a Monetary Policy Rule." Journal of Monetary Economics 43(3):607-654.

Svensson, Lars E.O. 2002. "Inflation Targeting: Should it be Modeled as an Instrument Rule or a Targeting Rule?" European Economic Review 46(4-5):771-780.

Svensson, Lars E.O. and Michael Woodford. 2005. Limits to Inflation Targeting. In Implementing Optimal Policy through Inflation-Forecast Targeting, ed. Ben S. Bernanke and Michael Woodford. Chicago: The University of Chicago Press pp. 19-91.

Tang, Jenny. 2015. Uncertainty and the Signaling Channel of Monetary Policy. Working Paper 15-8 Federal Reserve Bank of Boston. 
Walsh, Carl. 1995. "Optimal Contracts for Central Bankers." American Economic Review $85: 150-167$.

Walsh, Carl. 2015. "Goals and Rules in Central Bank Design." International Journal of Central Banking 11(S1):295-352.

Warsh, Kevin. 2017. "America Needs a Steady, Strategic Fed." Wall Street Journal. January 30.

Woodford, Michael. 2005. Central-Bank Communication and Policy Effectiveness. In The Greenspan Era: Lessons for the Future. Jackson Hole, Wyoming: Federal Reserve Bank of Kansas City pp. 399-474.

Wu, Jing Cynthia and Fan Dora Xia. 2016. "Measuring the Macroeconomic Impact of Monetary Policy at the Zero Lower Bound." Journal of Money, Credit, and Banking 48(2-3):253-291. 


\section{Appendix A New Keynesian Model of Inflation and Out- put}

In this appendix, we extend the intuition built in Section 3 to a model in which inflation and output are jointly determined, and show that a similar mapping from bands and horizons to a policy parameter exists. We use a simple forward-looking model, and discuss communication in cases with demand and supply shocks.

\section{A.1 Model Setup}

The model is a simple New Keynesian model where inflation and output are jointly determined by supply and demand shocks. The two equations describing the private economy are the log-linearized equations derived from a consumption Euler equation

$$
x_{t}=\mathbb{E}_{t}\left[x_{t+1}\right]-\sigma^{-1}\left(i_{t}-\mathbb{E}_{t}\left[\pi_{t+1}\right]\right)+g_{t},
$$

and an aggregate supply condition

$$
\pi_{t}=\beta \mathbb{E}_{t}\left[\pi_{t+1}\right]+\kappa x_{t}+u_{t}
$$

where $x_{t}$ denotes the output gap, $g_{t}$ is an aggregate demand shock, $u_{t}$ is an aggregate supply shock. The shocks follow autoregressive processes given by

$$
g_{t}=\rho_{g} g_{t-1}+\varepsilon_{g, t}
$$

and

$$
u_{t}=\rho_{u} u_{t-1}+\varepsilon_{u, t}
$$

with, for $j \in\{g, u\}, 0 \leq \rho_{j}<1$, and $\varepsilon_{j, t}$ is i.i.d. with mean zero. Monetary policy is given by a Taylor rule of the form

$$
i_{t}=\alpha \pi_{t}+\eta_{t}
$$

Again, by log-linearizing around the appropriate steady state, we have required a point inflation target for the monetary authority.

As in the Fisherian example, we consider an equilibrium where the monetary authority follows a rule and must provide communication that follows and hence reinforces that rule. The 
monetary authority simply giving the stance of policy $i_{t}$ does not pin down a unique value of the policy parameter $\alpha$ and the deviation from the rule $\eta_{t}$. Of course, it could communicate its policy rule by stating values of $\alpha$, but as noted in Section 2, this communication strategy is not embraced by central banks around the world. Instead, they tend to prefer giving bands around the inflation target as well as forecasts.

Following the same logic as used in the Fisherian economy, provided the Taylor principle $(\alpha \geq 1)$ holds, a unique solution is given by

$$
\pi_{t}=\frac{\kappa}{1+\kappa \sigma^{-1} \alpha-\Phi_{g}} g_{t}+\frac{1-\rho_{u}}{1+\kappa \sigma^{-1} \alpha-\Phi_{u}} u_{t}+\frac{\kappa \sigma^{-1}}{1-\alpha \kappa \sigma^{-1}} \eta_{t}
$$

for inflation, and

$$
x_{t}=\frac{\left(1-\beta \rho_{g}\right)}{1+\kappa \sigma^{-1} \alpha-\Phi_{g}} g_{t}-\frac{\sigma^{-1}\left(\alpha-\rho_{u}\right)}{1+\kappa \sigma^{-1} \alpha-\Phi_{u}} u_{t}+\frac{\sigma^{-1}}{1-\alpha \kappa \sigma^{-1}} \eta_{t}
$$

for output, where

$$
\Phi_{z}=\rho_{z}\left(1+\kappa \sigma^{-1}+\beta\left(1-\rho_{z}\right)\right) \quad \text { for } z \in\{g, u\} \text {. }
$$

Given that the shocks $\varepsilon_{g, t}, \varepsilon_{u, t}$, and $\eta_{t}$ are i.i.d., expected inflation is given by

$$
\mathbb{E}_{t}\left[\pi_{t+j}\right]=\frac{\kappa}{1+\kappa \sigma^{-1} \alpha-\Phi_{g}} \rho_{g}^{j} g_{t}+\frac{1-\rho_{u}}{1+\kappa \sigma^{-1} \alpha-\Phi_{u}} \rho_{u}^{j} u_{t}
$$

and the expected output gap equals

$$
\mathbb{E}_{t}\left[x_{t+j}\right]=\frac{1-\beta \rho_{g}}{1+\kappa \sigma^{-1} \alpha-\Phi_{g}} \rho_{g}^{j} g_{t}-\frac{\sigma^{-1}\left(\alpha-\rho_{u}\right)}{1+\kappa \sigma^{-1} \alpha-\Phi_{u}} \rho_{u}^{j} u_{t} .
$$

Note that, similar to equation (6), that these two equations are functions of the structural parameters governing the economy, as well as the policy parameter $\alpha$.

\section{A.2 Demand Shocks}

We first consider a monetary authority facing a demand shock. As in the Fisherian model, the monetary authority can communicate that, given a current value for the demand shock $g_{t}$, that it expects "inflation will be $\mu$ from the inflation target in $N_{t}$ periods," and from equation (28) 
this communication satisfies

$$
\mu=\mathbb{E}_{t}\left[\pi_{t+N}\right]=\frac{\kappa}{1+\kappa \sigma^{-1} \alpha-\Phi_{g}} \rho_{g}^{N} g_{t}
$$

Conditional on policy rule parameters $\alpha$, there is a continuum of choices for guidance on the tolerance $\mu$ and the horizon $N_{t}$. The inflation target cannot be hit in finite time, so $\mu=0$ remains impossible in this case. In addition, as with the Fisherian model, the communication of a tolerance $\mu$ and horizon $N_{t}$ is invertible in the sense that the mapping for $\alpha$ is given by

$$
\alpha=\frac{\frac{\kappa \rho_{g}^{N} g_{t}}{\mu_{\pi}}+\Phi_{g}-1}{\kappa \sigma^{-1}} .
$$

Given that under active policy $(\alpha \geq 1)$, inflation and the output gap move in the same direction, no guidance beyond the simple band and horizon is needed for communication of the rule. To see this fact, suppose the monetary authority announces "inflation will be $\mu$ from the inflation target in $N_{t}$ periods," which implies that $\alpha$ must satisfy the restriction in equation (31). In this case, the expected paths for inflation and the output gap are

$$
\mathbb{E}_{t}\left[\pi_{t+j}\right]=\rho_{g}^{j-N_{t}} \mu_{\pi} \text { and } \mathbb{E}_{t}\left[x_{t+j}\right]=\frac{1-\beta \rho_{g}}{\kappa} \rho_{g}^{j-N_{t}} \mu_{\pi},
$$

respectively. The key result in these equations is that providing communication about inflation directly pins down the expected paths for inflation and the output gap.

Figure 7 shows the case, given values for the structural parameters, with a 1pp demand shock $\left(g_{t}=1\right)$ and the monetary authority expresses a rule with a value of $\alpha_{0}$ by stating "inflation will be 0.5 percentage points from the inflation target in 16 periods." This communication pins down the policy parameter, as well as the dynamics for inflation, the output gap, and the nominal rate. In addition, as in the Fisherian model, if the policy parameter is a different value, this can be communicated via altering the horizon, and a smaller shock would imply a shorter horizon.

As in the Fisherian model, the inverse mapping from communication to the policy parameter after a demand shock is unique and has intuitive properties. Figure 8 shows for a $1 \mathrm{pp}$ demand shock, the implied policy parameter for given combinations of bands and horizons. Given a horizon, smaller values for the band imply stronger reactions to inflation; meanwhile, given a band size, longer horizons imply a weaker inflation response. 
Figure 7: Impulse Responses from a Demand Shock

(a) Inflation

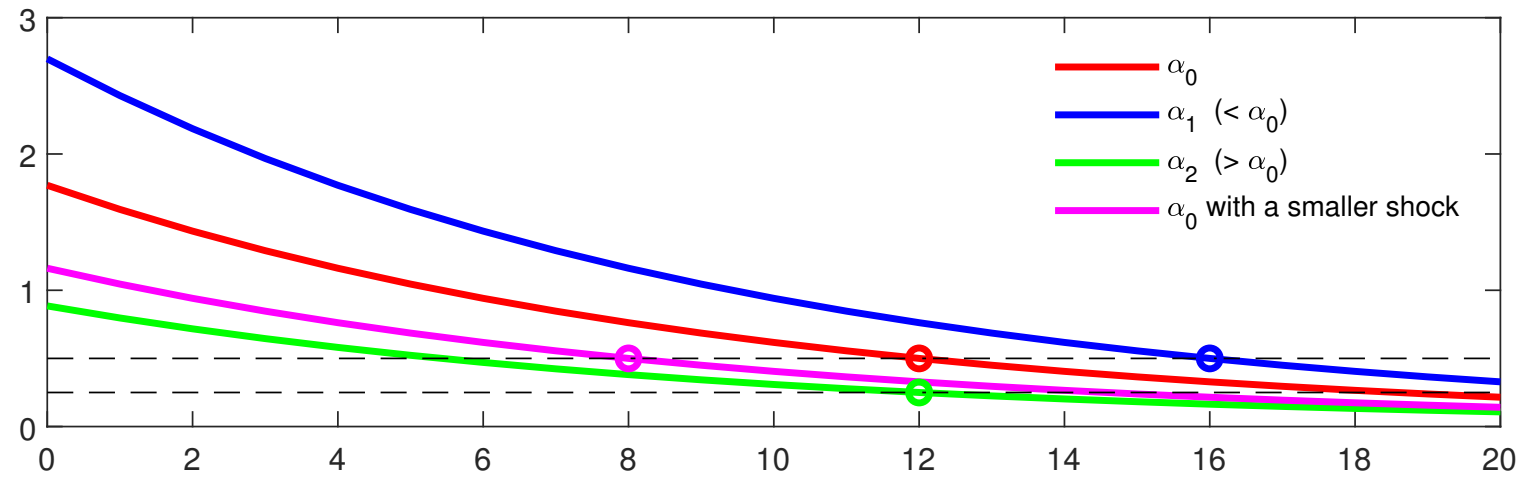

(b) Output Gap

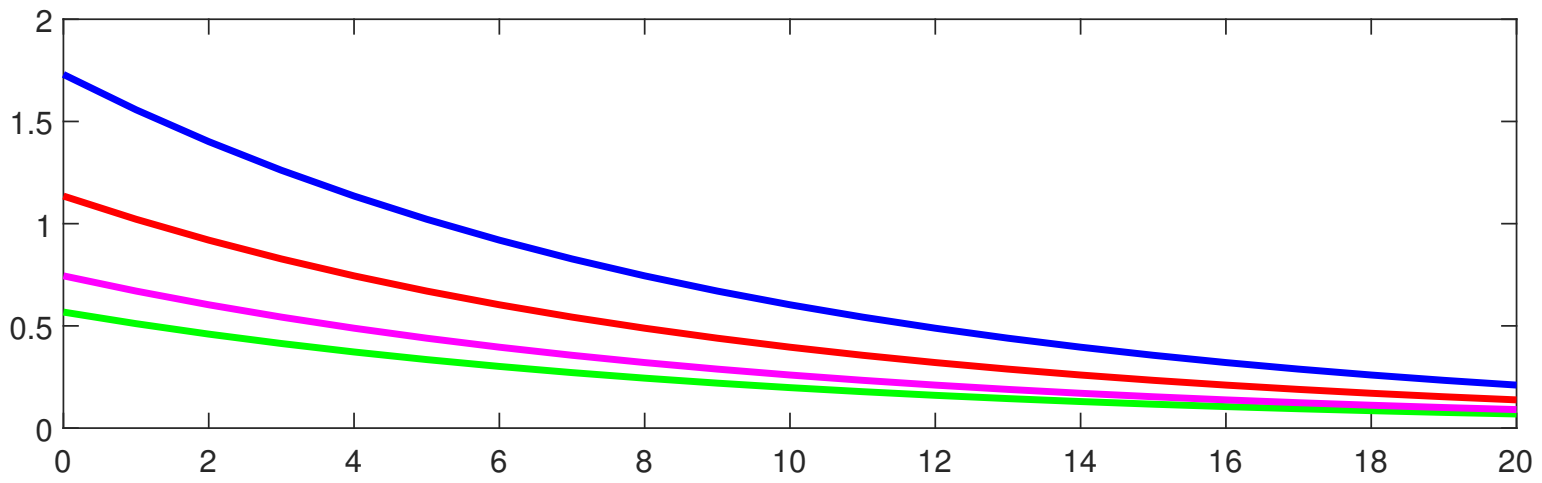

(c) Nominal Rate

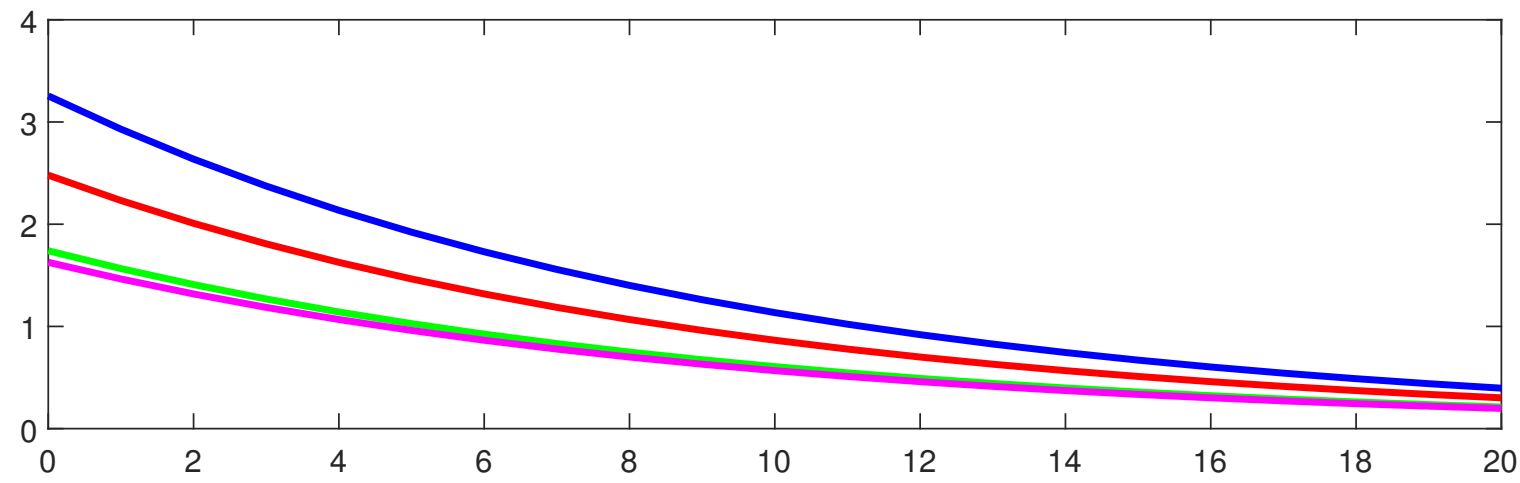

Note: Shows impulse responses to a $1 \mathrm{pp}$ shock (0.66pp in the smaller shock case) to demand when $\beta=0.99, \sigma=1, \kappa=0.17$, and $\rho_{g}=0.9$. Values for the policy parameters are $\alpha_{0}=1.40, \alpha_{1}=1.21$, and $\alpha_{0}=1.97$. 
Figure 8: Effective Communication Pins Down the Policy Parameter after a Demand Shock

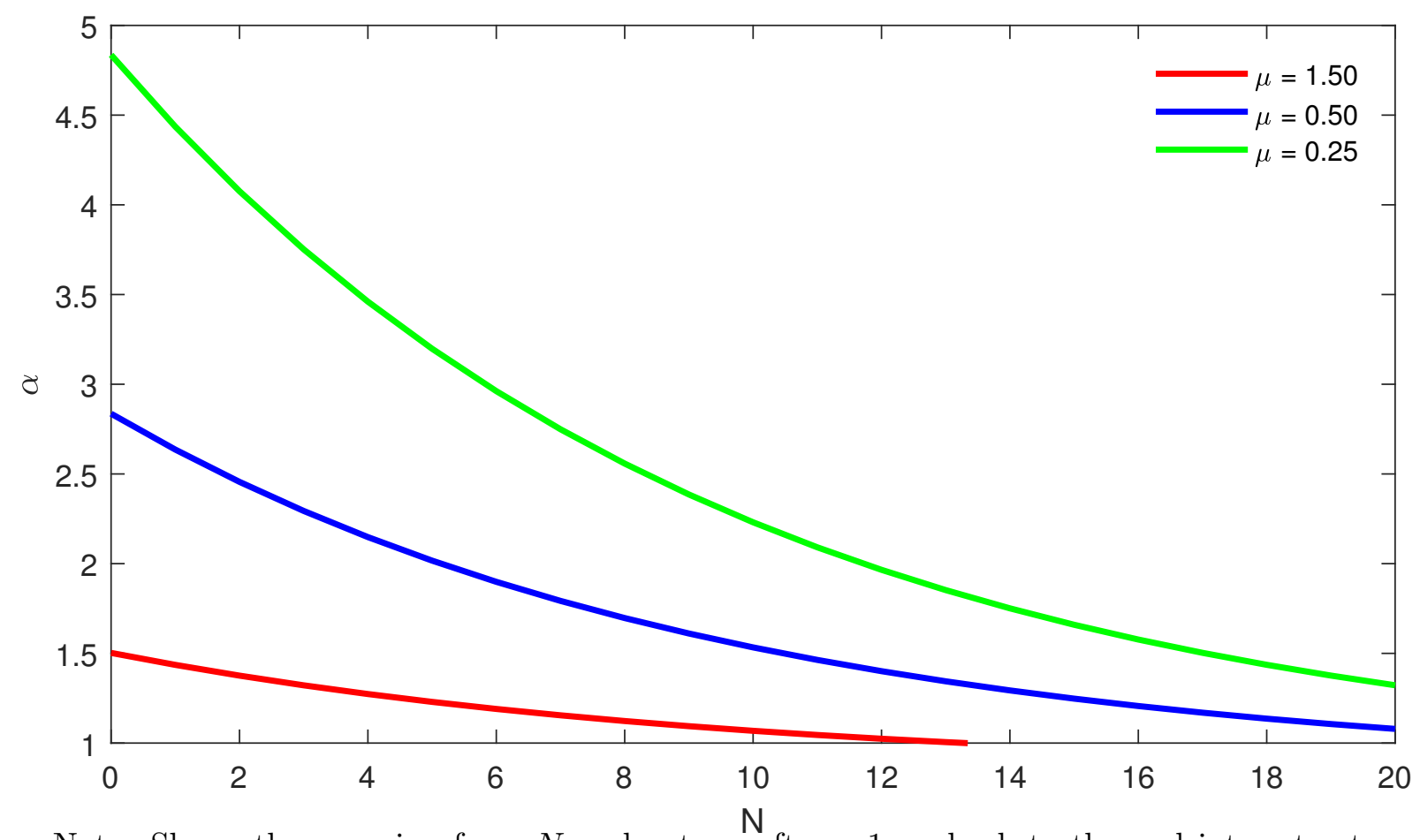

Note: Shows the mapping from $N$ and $\mu$ to $\alpha$ after a 1 pp shock to the real interest rate $\beta=0.99, \sigma=1, \kappa=0.17$, and $\rho_{u}=0.95$.

\section{A.3 Supply Shocks}

Now we consider a monetary authority that faces a supply shock. In this case, the monetary authority could communicate that after a supply shock of $u_{t}$, "inflation will be $\mu$ from the inflation target in $N_{t}$ periods," and from equation (28) this communication satisfies

$$
\mu=\mathbb{E}_{t}\left[\pi_{t+N}\right]=\frac{1-\rho_{u}}{1+\kappa \sigma^{-1} \alpha-\Phi_{u}} \rho_{u}^{N_{t}} u_{t} .
$$

Once again, there is a continuum of choices for guidance on the tolerance $\mu$ and the horizon $N_{t}$ conditional on policy rule parameter $\alpha$, although $\mu=0$ is not feasible in finite time. As in the case for a demand shock, the communication of a tolerance $\mu$ and horizon $N_{t}$ is invertible in the sense that the mapping for $\alpha$ is a function of the communication given the structural parameters. In this case, the monetary authority could communicate that after a supply shock of $u_{t}$, "inflation will be $\mu$ from the inflation target in $N_{t}$ periods," and from equation (28) this communication satisfies

$$
\alpha=\frac{\frac{1-\rho_{u}}{\mu} \rho_{u}^{N_{t}} u_{t}+\Phi_{u}-1}{\kappa \sigma^{-1}} .
$$


Similar to the demand shock only case, communication about inflation is sufficient to pin down the expected paths of inflation and the output gap if policy is active $(\alpha \geq 1)$. The above communication pins down $\alpha$ and the expected paths of inflation

$$
\mathbb{E}_{t}\left[\pi_{t+j}\right]=\rho_{u}^{j-N_{t}} \mu
$$

and the output gap

$$
\mathbb{E}_{t}\left[x_{t+j}\right]=-\frac{\sigma^{-1}}{1-\rho_{u}}\left(\frac{\frac{1-\rho_{u}}{\mu} \rho_{u}^{N_{t}} u_{t}+\Phi_{u}-1}{\kappa \sigma^{-1}}-\rho_{u}\right) \rho_{u}^{j-N_{t}} \mu
$$

The key result from these equations is the independence from $\alpha$, which highlights that providing communication about inflation directly pins down the expected paths for inflation, the output gap, and the interest rate without the need to specify the exact policy rule.

Figure 9 provides evidence that, given values for the structural parameters, after a 1pp supply

shock $\left(u_{t}=1\right)$, the monetary authority can express a rule with a value of $\alpha_{0}$ by stating "inflation will be 0.5 percentage points from the inflation target in 16 periods." This communication pins down the policy parameter, as well as the dynamics for inflation, the output gap, and the nominal rate. In addition, as in the Fisherian model, if the policy parameter is a different value, this can be communicated via altering the horizon, and a smaller shock would imply a shorter horizon.

Figure 10 shows the inverse mapping from communication after a supply shock retains the intuitive properties from the Fisherian model. A higher policy parameter can be communicated with a relatively tighter band, or a shorter horizon.

\section{A.4 Price Level Targeting}

In this section, we extend the communication strategy to an additional type of policy rule, that of price level targeting, and show the fundamental concept of bands and a horizon remains unchanged. Price level targeting is an interesting extension because it has a make-up component and has received attention in light of lower inflation and zero lower bound risk. More crucially, by changing from inflation to price level targeting, the target for monetary policy changes, leading to a necessary change in language. 
Figure 9: Impulse Responses from a Supply Shock

(a) Inflation

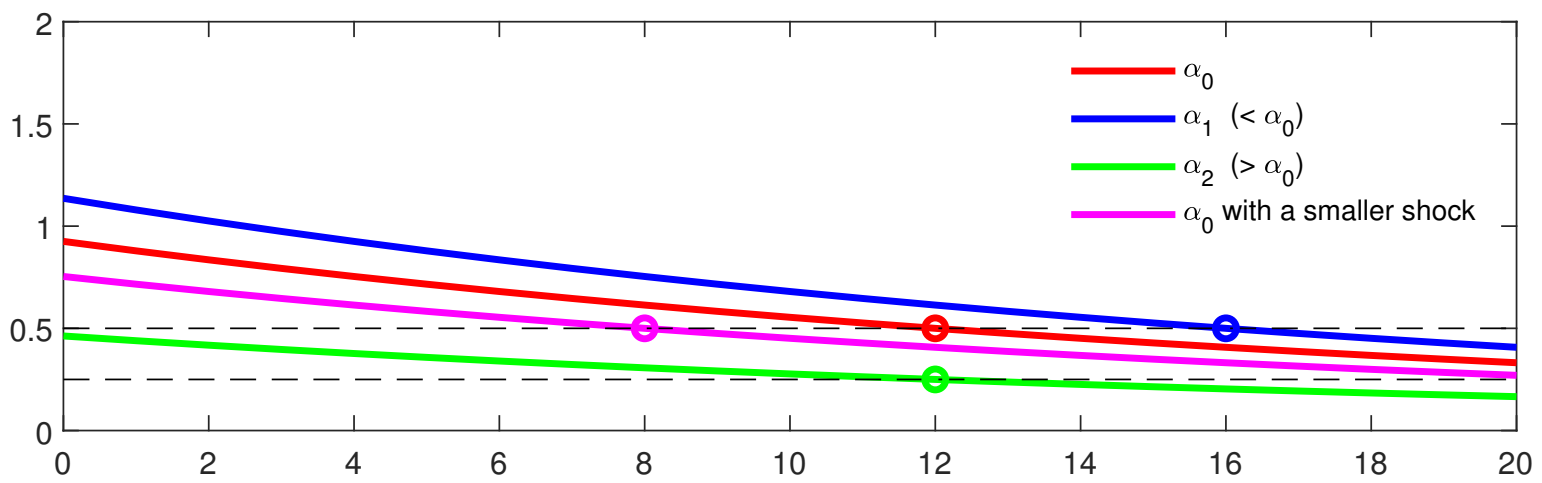

(b) Output Gap

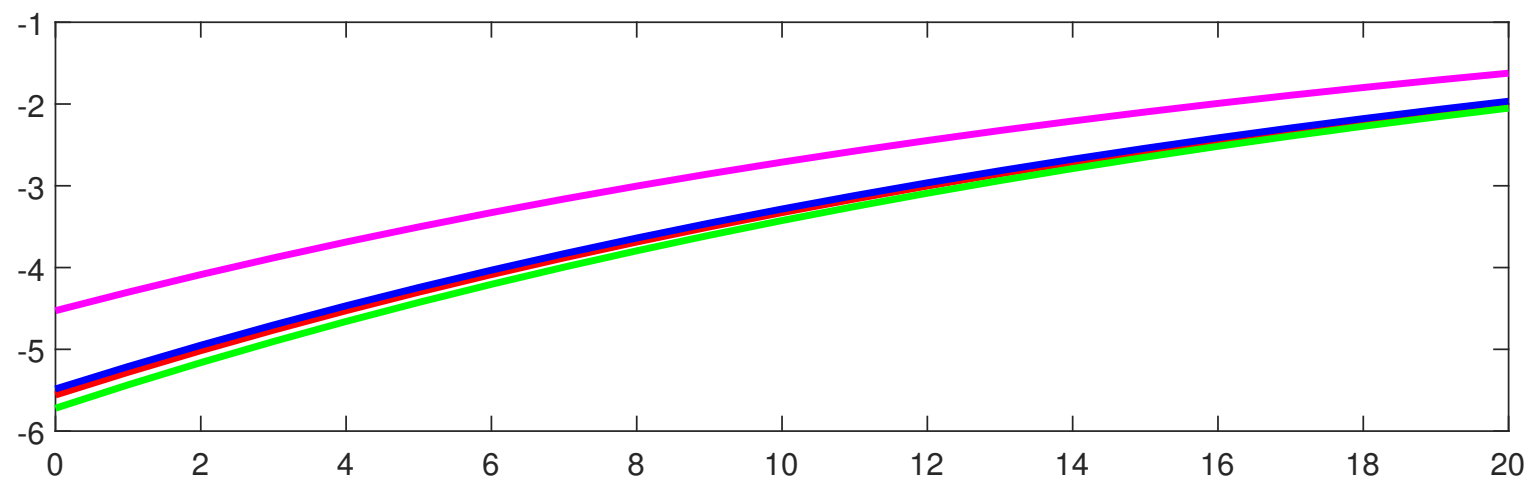

(c) Nominal Rate

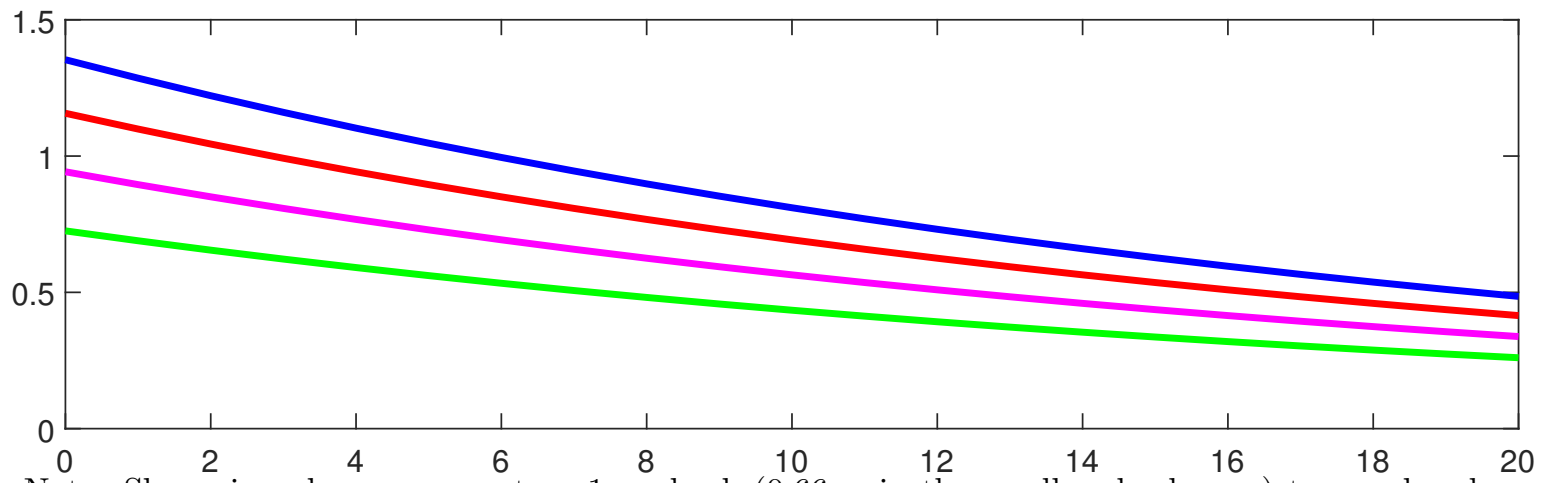

Note: Shows impulse responses to a $1 \mathrm{pp}$ shock (0.66pp in the smaller shock case) to supply when $\beta=0.99, \sigma=1, \kappa=0.17$, and $\rho_{u}=0.95$. Values for the policy parameters are $\alpha_{0}=1.25, \alpha_{1}=1.19$, and $\alpha_{0}=1.57$.

To illustrate this environment, we use an interest rate rule given by

$$
i_{t}=\alpha p_{t}+\eta_{t}
$$


Figure 10: Effective Communication Pins Down the Policy Parameter after a Supply Shock

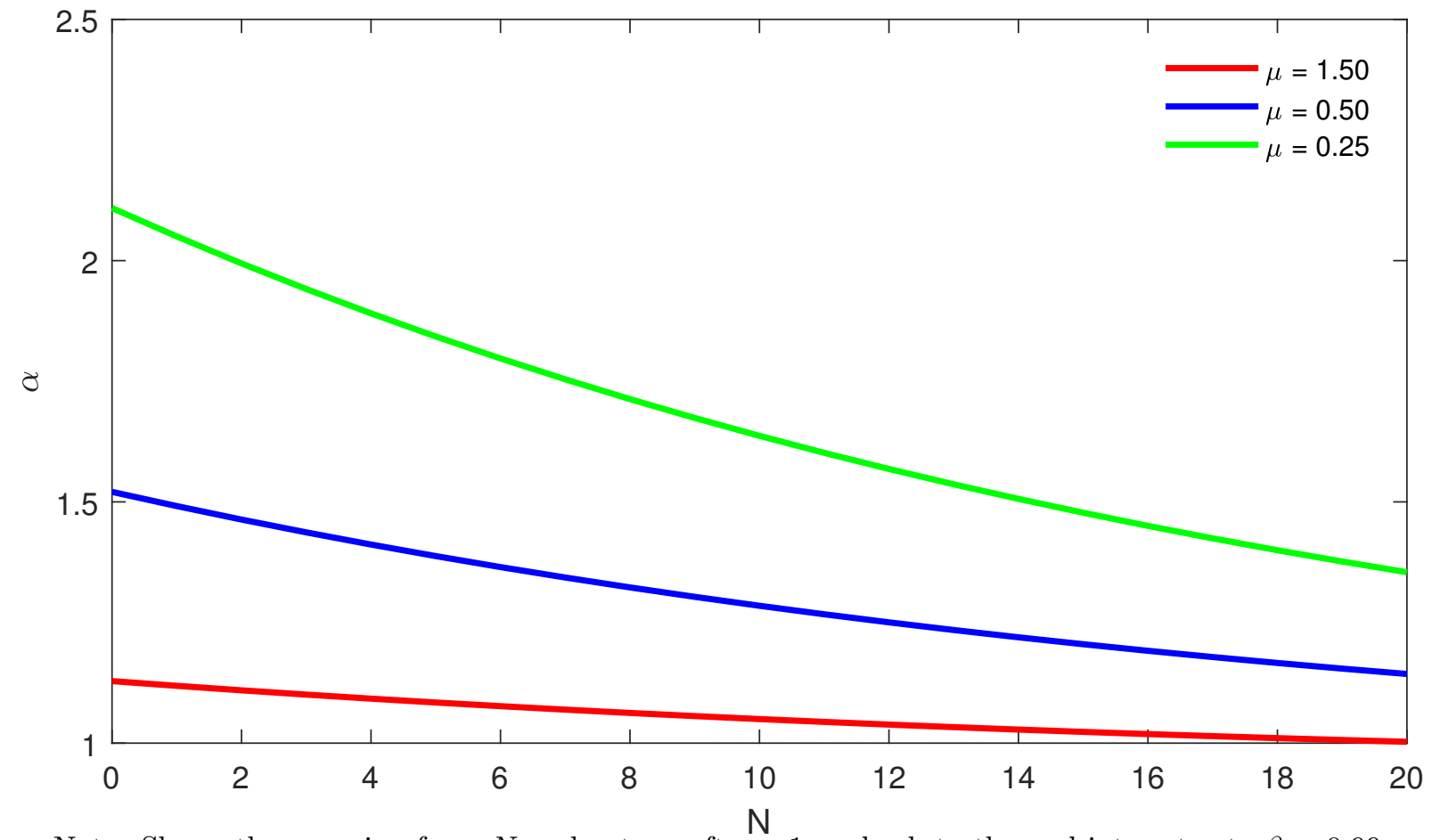

Note: Shows the mapping from $N$ and $\mu$ to $\alpha$ after a 1 pp shock to the real interest rate $\beta=0.99$, $\sigma=1, \kappa=0.17$, and $\rho_{u}=0.95$.

where $p_{t}$ denotes deviations from the price level, which follows

$$
p_{t}=p_{t-1}+\pi_{t} .
$$

As in the examples considered, a monetary authority simply giving the stance of policy $i_{t}$ does not pin down a unique value of the policy parameter $\alpha$ and the deviation from the rule $\eta_{t}$, and communicating $\alpha$ directly is not typically followed by central banks around the world. Again, the existence of an endogenous predetermined variable $p_{t-1}$ implies there is no longer a simple closed-form solution for $\pi_{t}$ and $x_{t}$, but instead there are solutions of the form

$$
\begin{aligned}
& \pi_{t}=\Gamma_{\pi p} p_{t-1}+\Gamma_{\pi g} g_{t}+\Gamma_{\pi u} u_{t}+\Gamma_{\pi \eta} \eta_{t} \\
& x_{t}=\Gamma_{x p} p_{t-1}+\Gamma_{x g} g_{t}+\Gamma_{x u} u_{t}+\Gamma_{x \eta} \eta_{t} \\
& p_{t}=\Gamma_{p p} p_{t-1}+\Gamma_{p g} g_{t}+\Gamma_{p u} u_{t}+\Gamma_{p \eta} \eta_{t}
\end{aligned}
$$


where $\Gamma_{j, k}$ are functions of $\alpha$. The expected path for the price level is

$$
\mathbb{E}_{t}\left[p_{t+j}\right]=\Gamma_{p p}^{j+1} p_{t-1}+\sum_{k=0}^{j} \Gamma_{p p}^{j-k} \rho_{g}^{k} \Gamma_{p g} g_{t}+\sum_{k=0}^{j} \Gamma_{p p}^{j-k} \rho_{u}^{k} \Gamma_{p u} u_{t}+\Gamma_{p p}^{j} \Gamma_{p \eta} \eta_{t},
$$

which implies

$$
\begin{aligned}
\mathbb{E}_{t}\left[\pi_{t+j}\right]= & \Gamma_{\pi p} \Gamma_{p p}^{j} p_{t-1}+\left(\Gamma_{\pi p} \sum_{k=0}^{j-1} \Gamma_{p p}^{j-1-k} \rho_{g}^{k} \Gamma_{p g}+\Gamma_{\pi g} \rho_{j}^{j}\right) g_{t} \\
& +\left(\Gamma_{\pi p} \sum_{k=0}^{j-1} \Gamma_{p p}^{j-1-k} \rho_{u}^{k} \Gamma_{p u}+\Gamma_{\pi u} \rho_{u}^{j}\right) u_{t}+\Gamma_{\pi p} \Gamma_{p p}^{j-1} \Gamma_{p \eta} \eta_{t}
\end{aligned}
$$

and

$$
\begin{aligned}
\mathbb{E}_{t}\left[x_{t+j}\right]= & \Gamma_{x p} \Gamma_{p p}^{j} p_{t-1}+\left(\Gamma_{x p} \sum_{k=0}^{j-1} \Gamma_{p p}^{j-1-k} \rho_{g}^{k} \Gamma_{p g}+\Gamma_{x g} \rho_{j}^{j}\right) g_{t} \\
& +\left(\Gamma_{x p} \sum_{k=0}^{j-1} \Gamma_{p p}^{j-1-k} \rho_{u}^{k} \Gamma_{p u}+\Gamma_{x u} \rho_{u}^{j}\right) u_{t}+\Gamma_{x p} \Gamma_{p p}^{j-1} \Gamma_{p \eta} \eta_{t}
\end{aligned}
$$

Assuming that the price level was previously was at target, communication after a 1pp demand shock that "inflation will be $\mu$ from the inflation target in $N_{t}$ periods" implies

$$
\mu=\mathbb{E}_{t}\left[p_{t+N}\right]=\sum_{k=0}^{j} \Gamma_{p p}^{j-k} \rho_{g}^{k} \Gamma_{p g}
$$

and similarly for a 1pp supply shock

$$
\mathbb{E}_{t}\left[p_{t+N}\right]=\sum_{k=0}^{j} \Gamma_{p p}^{j-k} \rho_{u}^{k} \Gamma_{p u}
$$

In this case of price level targeting, then, policy can be communicated with "the price level will be $\mu$ from the inflation target in $N_{t}$ periods." Figure 11 shows the case when, given values for the structural parameters, after a $1 \mathrm{pp}$ demand shock $\left(g_{t}=1\right)$ the monetary authority expresses a rule with a value of $\alpha_{0}$ by stating "the price level will be 0.25 percentage points from the inflation target in 8 periods." This communication pins down the policy parameter, as well as the dynamics for inflation, the output gap, and the nominal rate. A more dovish policy 
Figure 11: Impulse Responses with a Price Level Target Rule

(a) Price Level

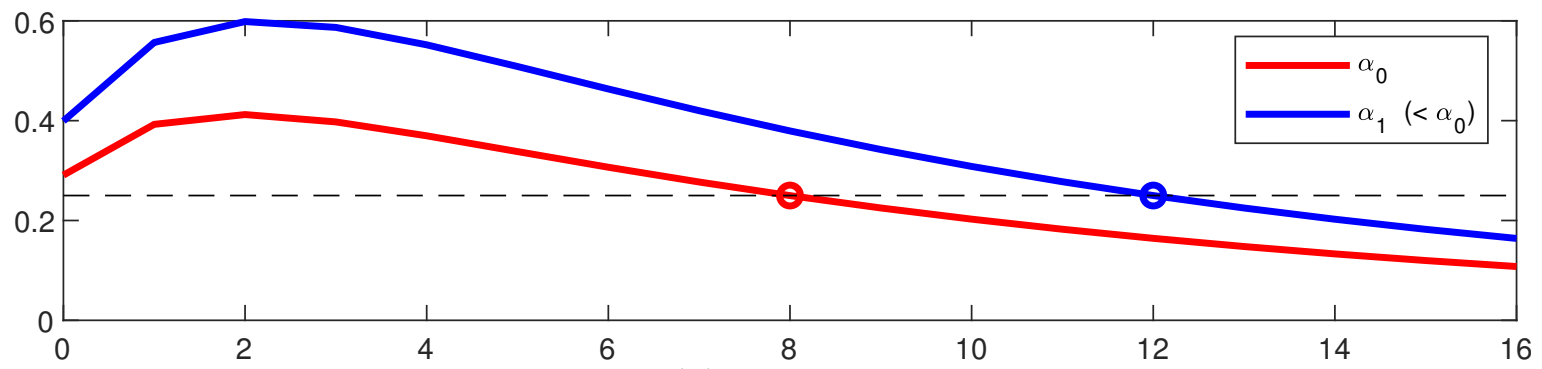

(b) Inflation

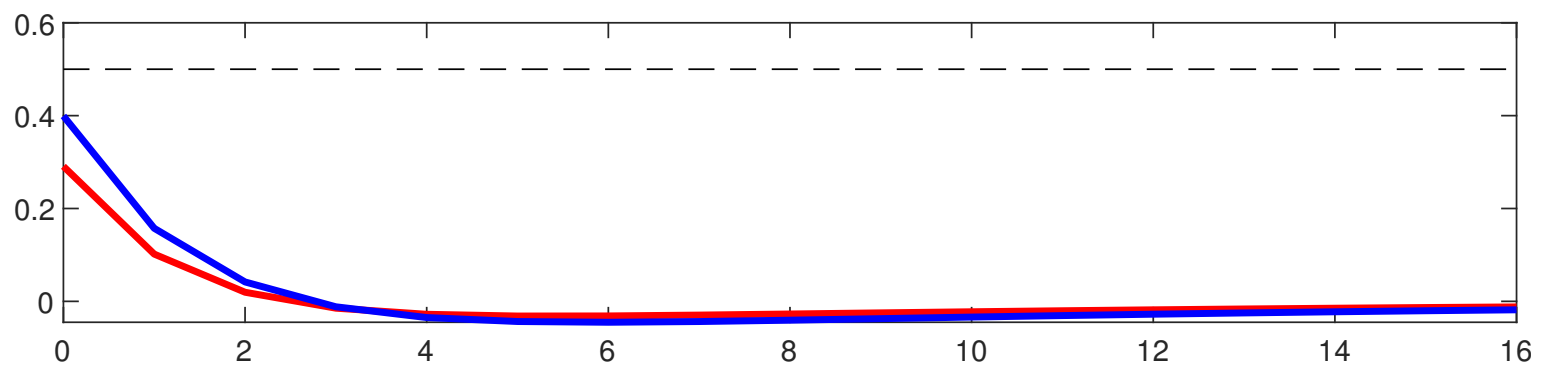

(c) Output Gap

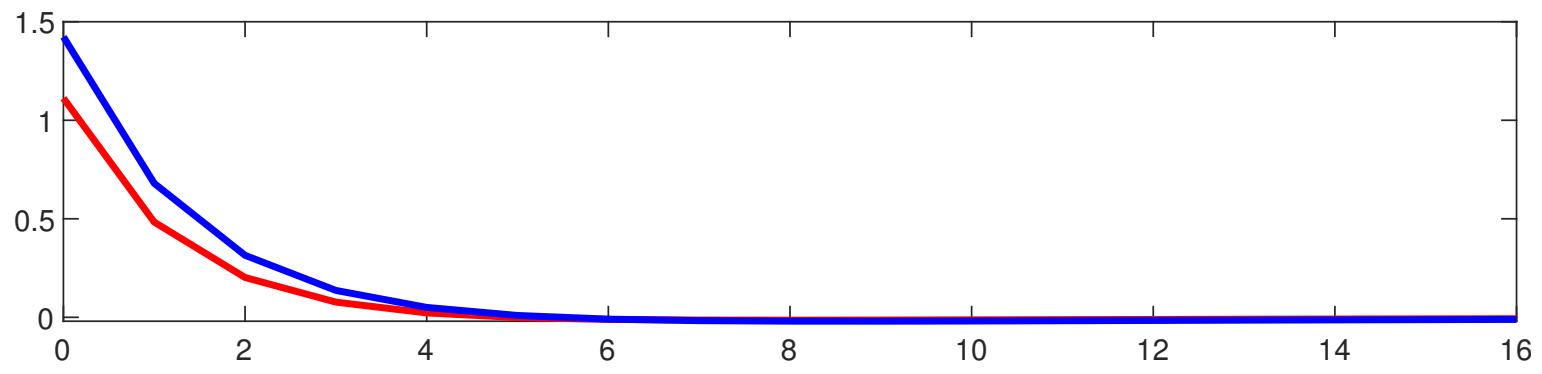

(d) Nominal Rate

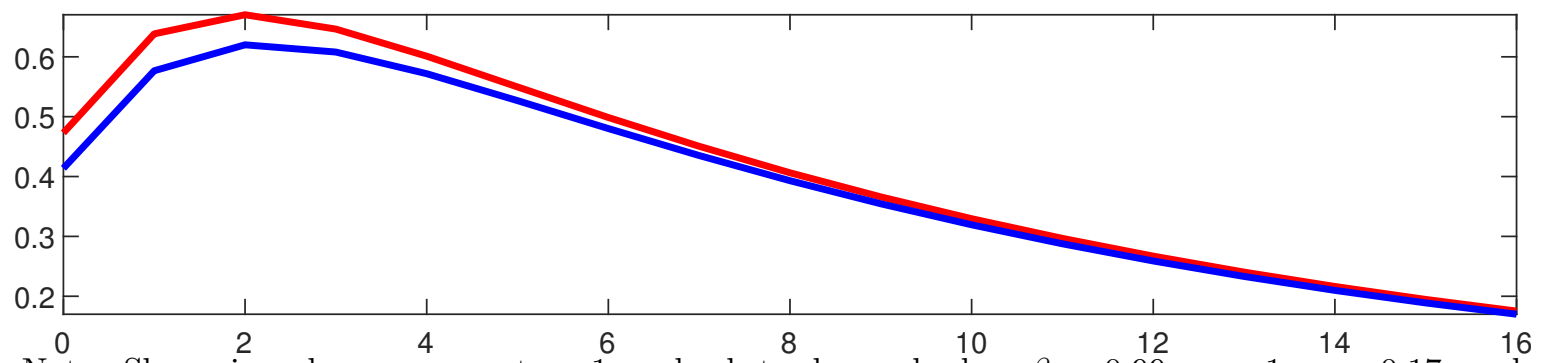

Note: Shows impulse responses to a 1pp shock to demand when $\beta=0.99, \sigma=1, \kappa=0.17$, and $\rho_{g}=0.9$. Values for the policy parameters are $\alpha_{0}=1.63$ and $\alpha_{1}=1.04$.

$\alpha_{1}$ can be communicated by stating "the price level will be 0.25 percentage points from the inflation target in 12 periods." These communications pin down inflation, the output gap, and 
the nominal rate. In addition, by changing communication to the price level, the central bank preserves the principles for measuring deviations as discussed in the previous section.

\section{Appendix B Additional Details on Hybrid New Keyne- sian Model}

To generate the series $\left\{N_{t}\right\}_{t}^{T}$ in Figure $4 \mathrm{~b}$, we start with the model given by (17)-(19)

$$
0=F_{y} \mathbb{E}_{t}\left[Y_{t+1}\right]+F_{y, L} Y_{t}+F_{x} X_{t}+F_{x, L} X_{t-1}+G \varepsilon_{t}
$$

where $Y_{t}=\left[\pi_{t}, x_{t}, i_{t}, \Pi_{t}\right], \Pi_{t}$ denotes annual inflation, and $X_{t}=\left[\pi_{t}, \pi_{t-1}, \pi_{t-2}, x_{t}, x_{t-1}, x_{t-2}, x_{t-3}\right]$, with solution

$$
\begin{aligned}
& Y_{t}=G_{x} X_{t-1}+G_{\varepsilon} \varepsilon_{t}, \\
& X_{t}=H_{x} X_{t-1}+H_{\varepsilon} \varepsilon_{t} .
\end{aligned}
$$

Note that all elements of $\left\{Y_{t}, X_{t}\right\}$ are observables.

For a given $\alpha$ and values for the structural parameters given in Section 4.1, the value of $N_{t}$ is the $j$ for which $\mathbb{E}_{t} \Pi_{t+j}=0.25$, where $\mathbb{E}_{t} \Pi_{t+j}=G_{x, \pi} H_{x}^{j} X_{t+j-1}$, where $G_{x, \pi}$ is the row of $G_{x}$ that corresponds to the solution for $\Pi_{t}$. Note that $N_{t}$ is simply the expected number of periods it will take inflation to move within $\mu$ of the target at each point in the sample.

We then solve the following problem

$$
\min _{\alpha \in\left[\alpha_{\min }, \alpha_{\max }\right]} \sum_{t=1}^{T}\left|E_{t}\left[N_{t}\right]-N_{t}^{a c t}\right| \text { s.t. }(45-46),
$$

where $N_{t}^{a c t}$ is the ex-post realized or actual number of periods it took from time $t$ for inflation to move within $\mu=0.25$ of the target. We interpret the solution to this problem as the $\alpha$ the public would have inferred if the Fed had communicated a tolerance band of $\mu=0.25$ and $\left\{N_{t}\right\}_{t}^{T}$ given by the values shown in Figure $4 \mathrm{~b}$. 